\title{
Effect of allopurinol and hemin on some biological markers of aging in broiler chickens
}

Dinesh Singh Rathore

West Virginia University

Follow this and additional works at: https://researchrepository.wvu.edu/etd

\section{Recommended Citation}

Rathore, Dinesh Singh, "Effect of allopurinol and hemin on some biological markers of aging in broiler chickens" (1999). Graduate Theses, Dissertations, and Problem Reports. 985.

https://researchrepository.wvu.edu/etd/985

This Thesis is protected by copyright and/or related rights. It has been brought to you by the The Research Repository @ WVU with permission from the rights-holder(s). You are free to use this Thesis in any way that is permitted by the copyright and related rights legislation that applies to your use. For other uses you must obtain permission from the rights-holder(s) directly, unless additional rights are indicated by a Creative Commons license in the record and/ or on the work itself. This Thesis has been accepted for inclusion in WVU Graduate Theses, Dissertations, and Problem Reports collection by an authorized administrator of The Research Repository @ WVU. For more information, please contact researchrepository@mail.wvu.edu. 
Effect of Allopurinol and Hemin on Some Biological Markers of Aging in Broiler Chickens

\author{
Dinesh Singh Rathore \\ Thesis submitted to the Faculty of \\ Agriculture, Forestry and Consumer Sciences \\ West Virginia University \\ in the partial fulfillment of the requirements for the degree of
}

\author{
Master of Science \\ in \\ Animal and Veterinary Sciences
}

H. Klandorf, Chair

W. J. Kaczmarczyk

J. Killefer

D. Porter

Morgantown, West Virginia

1999

Keyword: Aging, Allopurinol, Diet restriction, Hemin, Pentosidine, Meat quality, Uric acid,

Copyright 1999, Dinesh Singh Rathore 


\title{
Effect of Allopurinol and Hemin on Some Biological Markers Of Aging in Broiler Chickens
}

\author{
Dinesh Singh Rathore
}

\begin{abstract}
$\underline{\text { Abstract }}$
Uric acid has been hypothesized as one of the most important antioxidants in limiting the accumulation of advanced glycolated endproducts in broiler breeder hens. This study was designed to quantitatively manipulate the plasma uric acid concentrations using hemin and allopurinol and determine its effect on skin pentosidine, shear force value of Pectoralis major muscle, plasma glucose, body and breast weight, and chemiluminescence induced oxidative stress in broiler chickens. Allopurinol decreased plasma uric acid, ranging from $26 \%$ to $74 \%$, with the most pronounced effect at wk 22. Hemin increased plasma uric acid concentrations between 11 and 14\%. Skin pentosidine levels increased $(\mathrm{P}<0.05)$ in the allopurinol fed birds, in both ad libitum and diet restricted, at $22 \mathrm{wk}$ of age and in hemin fed birds at wk 22. The reduction in uric acid concentration was associated with an increase in the level of oxidative stress, which can be linked to the increase in tissue skin pentosidine, thus advancing the decline in meat tenderness.
\end{abstract}

Keywords: uric acid, allopurinol, hemin, pentosidine, oxidative stress, shear force 


\section{Dedication}

To my mother, Shrimati Sheelwati Rathore and father, Shri Kushal Pal S Rathore

who by their precept and example made me love

all creatures great and small 


\section{$\underline{\text { Acknowledgement }}$}

I wish to express my sincere gratitude to my major advisor, Dr. Hillar Klandorf for his constant encouragement, skillful advice and helpful counsel, which he offered throughout this study. My sincere appreciation is also extended to Dr J. Killefer, Dr D. Porter and Dr W.J.Kaczmarczyk for their generosity in providing valuable suggestions, useful inputs and criticism. I would like to acknowledge the help of Dr E. Townsend in statistical analysis and to the encouragement extended by Dr John Warren.

Thanks are also extended to Mr. Nabil Al-Humadi of National Institute of Occupational and Safety Health in modification and standardization of HPLC procedure for pentosidine estimation, and to Dr Knox Van Dyke of Robert C Byrd WVU School of Medicine for help in estimation of CL induced oxidative stress.

While I acknowledge the valuable contribution, facilities and generous help extended by the poultry farm crew, my special thanks go to Mr. W. T. Jones and Mr. Glen Knuckle for help in husbandry and management of experimental flock. I also acknowledge the generous help received from Dr. Brett Kenney, Ms. Susan Slider and Ms. Diana Keller.

I am grateful to the West Virginia University for awarding me the graduate research assistantship, which is duly acknowledged. For making my stay most pleasant in and outside the laboratory I am indebted to my friends. A big "Thank You" to all but, in particular, I would like to mention: Iqbal Muhammad, Scott Gahr, Rajesh Nayak, Hakan Kocamis, W. Mangoli, Justin Mwashy, M. Simoyi and Rajeev Arora. Gerald L Shane deserves my sincere appreciation for being a friend. The feeling that Morgantown as a "second home" to me was in a large part due to him. Thank you, Jerry. 
I am indebted to my wife Sunita, son Siddhartha and daughter Malvika for their love, support and appreciation. I could not have played the role of a non-traditional student, a husband and a father without their deep understanding.

Finally, to my parents Shri and Shrimati Kushal Pal S Rathore and Sheelwati S Rathore, mere words can not be an adequate testimony to all that they have bestowed upon me. To them, I am truly indebted.

\section{Morgantown, WV}

Dinesh S Rathore 
And God blessed them, saying, be fruitful, and multiply, and fill the water in the seas, and let fowl multiply in the earth.

\section{GENESIS 1: 20.23}




\section{$\underline{\text { Table of Contents }}$}

$\underline{\text { Item }}$

Page

Chapter 1

Introduction

Chapter 2

Review of Literature

- Aging in Mammals: The Process and do the Theories explain it?

- Birds as Animal Models of Aging

- Pentosidine: An Aging Marker in Birds?

- Uric Acid: An Antioxidant Evaluation

- Uric Acid Manipulation

- Diet Restriction and Aging

- Oxidative Stress and Cellular Chemiluminescence

Chapter 3

Study 1

Accelerated Tissue Aging and Increased Oxidative Stress in Broiler Chickens fed Allopurinol

1. Abstract

2. Introduction

3. Material and Methods 
$\checkmark$ Birds and Management $\quad 26$

$\checkmark$ Electron Spin Resonance (ESR) Measurement 27

$\checkmark$ Pentosidine (Ps) Determination $\quad 28$

$\checkmark$ Breast Weight, Cooking Time and Shear Value Evaluation 29

$\checkmark$ Uric Acid and Glucose Determination $\quad 30$

$\checkmark$ Measurement of Luminol-Based Chemiluminescence (LBCL) $\quad 30$ Oxidative Stress

4. Statistical Analysis

5. Results

6. Discussion

7. Acknowledgements

8. References

Study 2

Effect of Uric Acid Manipulation on Ventricular Hypertrophy and Oxidative Stress in Broiler Chickens

1. Abstract

2. Introduction

3. Material and Methods

$\checkmark$ Birds and Management

$\checkmark$ Uric Acid Determination

$\checkmark$ Measurement of Right Ventricular Hypertrophy

$\checkmark$ Measurement of Luminol-Based Chemiluminescence (LBCL) 56 Oxidative Stress

4. Statistical Analysis 
$\begin{array}{llr}\text { 5. } & \text { Results } & \mathbf{5 7}\end{array}$

$\begin{array}{ll}\text { 6. Discussion } & 58\end{array}$

$\begin{array}{lll}\text { 7. } & \text { References } & 61\end{array}$

Chapter 4

$\begin{array}{ll}\text { Summary } & 70\end{array}$

Chapter 5

Bibliography 
Study 1

Table 1. Mean and SE of Body Weight, Breast Weight, Cook Time, 45 Shear Force, Heart Weight and RV:TV Ratio

Table 2. Mean and SE of Uric Acid, Glucose, Total Leukocyte Count, 46 Oxidative Stress and Pentosidine in Allopurinol and Hemin treated Broiler Chickens

Figure 3. Effect of Allopurinol/Hemin on Plasma Uric Acid

Figure 4. Effect of Allopurinol/Hemin on Skin Pentosidine

Figure 5. Effect of Allopurinol/Hemin on Oxidative Stress

Figure 6. Effect of Allopurinol/Hemin on Breast Weight

Figure 7. Effect of Allopurinol/Hemin on Shear Force

Figure 8. Effect of Allopurinol/Hemin on Body Weight

Study 2

Figure 1. Effect of Allopurinol/Hemin on RV:VT Ratio

Figure 2. Effect of Allopurinol/Hemin on Heart Weight

Figure 3. Effect of Allopurinol/Hemin on Breast Muscle Weight

Figure 4. Effect of Allopurinol/Hemin on Chemiluminescence based Oxidative Stress

Figure 5. Effect of Allopurinol/Hemin on Total Leukocyte Count 


\section{LIST OF ABBREVIATIONS}

$\begin{array}{ll}\text { AGEs } & \text { advanced glycolated endproducts } \\ \text { AL } & \text { ad libitum } \\ \text { DR } & \text { diet restricted } \\ \text { ESR } & \text { electron spin resonance } \\ \text { LBCL } & \text { luminol based chemiluminescence } \\ \text { LV+S } & \text { left ventricle plus septum } \\ \text { Ps } & \text { skin pentosidine } \\ \text { RV } & \text { right ventricle } \\ \text { RV:TV } & \text { ratio of right ventricle to total ventricle } \\ \text { SV } & \text { shear value } \\ \text { TLC } & \text { total leukocyte count }\end{array}$




\section{Chapter 1}

\section{INTRODUCTION}

It is estimated that by the year 2010, world production of poultry meat will have increased to 55,316,000 tons, making it the most widely consumed meat in the world ( Summers, 1998). It also implies that poultry production will increase at a fast pace. The broiler chicken of today is truly remarkable. Superior genetics has resulted in increased body weight gains, increased yields, and increased efficiency of feed utilization. Looking at the past few decades, it can be said that growth rate gains due to selection have been substantial, and while may not be ebbing, peak performance may be fast approaching. Looking at the future, further improvements could possibly result from applying tools in molecular biology to breed specific meat types, understanding and ameliorating pathologic disorders resulting due to rapid growth rates and consequent shift in homeostasis, adapting husbandry conditions to nutritional and environmental concerns and by prolonging the reproductive life span. In fact, increasing the reproductive life span seems to be a worthwhile goal for poultry breeders.

The study of life span, both in mammals and aves, and as to why one ages has been one of the most intriguing questions of our time. Aging refers to the large array of alterations in the structure and function that slowly and insidiously unfold during the post maturational phases of the life course (Martin et al., 1997). Many of these alterations are pathologic while others may be compensatory. The sum of these degenerative changes eventually leads to a progressive increase in the force of mortality and decrease in reproductive rates in almost all organisms.

There are many theories that describe the changes and explain why aging occurs. However there is no systematic overview of all the theories. The main theories indicate that aging may be caused due to mutations taking place in the somatic cells, errors in DNA transcription and translation resulting in defective protein or the age dependent loss of all 
physiological abilities affecting functions of various parts of the body leading to wear and tear. Other theories relate aging to formation of intra and/ or intermolecular crosslinks which are able to alter the structure of macromolecules to such an extent that their function has also becomes altered, or to the accumulation of substances which may lead to an impairment of the cellular functions after a certain time. Currently, the "Membrane Theory of Aging" is gaining ground and it states that free radicals induce cross linking of proteins and lipids and decrease the $\mathrm{Pk}$ of the cell membrane leading to condensation of cell colloidal system leading to decreased enzyme activity.

Aging has been studied in many animal models, but the avian species have not been well studied. People often question the choice of birds as animal model of aging. Why use birds? Birds offer manifold advantages as animal models for biogerontology. The maximum longevity in birds has been known to range from 4 years in blue jay ( Cyanocitta cristata) to 64 years in Macaw ( Ara macao). Their chief features relative to aging research are many and have been reviewed (Holmes and Austad, 1994). These traits include: (1) metabolic rates as much as 2 to 2.5 times as those of mammals of similar body sizes. (2) blood sugar levels typically 2 to 4 times as high as those of mammal's (3) an elevated body temperature, about $3^{\circ} \mathrm{C}$ higher than mammals. These factors expose them to a higher rate of free oxygen radical production and accelerate formation of advanced Maillard products. Without special protective mechanisms against the potential for damage, birds should be comparatively short lived and age more rapidly than mammals. Therefore, an inquiry into the physiological mechanisms allowing birds to achieve their extended life spans will facilitate an understanding of basic aging process against them. It has also been observed that species with high levels of circulating antioxidants, particularly alpha tocopherols, carotenoids and uric acids had higher life spans than those with 
lower concentrations (Cutler, 1984). It appears that birds have evolved mechanisms to limit the damage caused by these degenerative changes. Uric acid has been proposed as a potent scavenger of free radicals in human and many animal tissues (Hellsten et al., 1997). It has been demonstrated that urate, in vitro, has the ability to scavenge peroxides, hydroxyl radical species and hypochlorus acid. It is estimated to supply $30-65 \%$ of the peroxyl radical scavenging ability (Becker, 1991). Thus, there is a critical need to evaluate the role of uric acid as an antioxidant. It is in this context that the present study was thought of and initiated.

The present study had the following objectives:

- To determine if Allopurinol and Hemin, could be used in effecting changes in uric acid levels in broiler chickens. . Allopurinol is a structural analogue of the natural purine base, hypoxanthine and is a potent inhibitor of xanthine oxidase, the enzyme that converts hypoxanthine to xanthine and of xanthine to uric acid (Bartges et. Al., 1997). Hemins on the other hand potentates the level of uric acid (Miller et. Al., 1995).

- To determine if the changed uric acid levels, were influenced by diet regime (feed restricted vs ad libitum feeding

- To determine if any relationship could be established between the allopurinol/hemin intake level and aging markers, particularly skin pentosidine.

- To determine how changed uric acid levels influence breast weight and sheer force in broiler chickens 


\section{Chapter 2}

\section{REVIEW OF LITERATURE}

\section{Aging in mammals: The process and, do the theories explain it?}

In modern gerontological terms aging is a time dependent biological process. It usually denotes the phenomenon or processes having to do with the deterioration and dying out of all members of a population of animals in a highly predictable and characteristic fashion. Deterioration and death occurs inspite of best possible nutrition, environment and combination of genes. The fact that these changes in populations occur in such predictable fashion tells us that aging is as much a part of normal biology as growth and differentiation. Changes also occur at the molecular and tissue level (Kohn, 1978). According to Strehler (1959), the following main features can characterize the aging process:

1. It is destructive and decreases the functional ability.

2. It is progressive and irreversible.

3. It is universal.

His fourth characteristic of aging being wholly intrinsic is however debatable and now extrinsic factors are thought to play a major role.

A considerable knowledge of ours about the aging process, disease incidence and physiological changes in aging has come from very useful work with laboratory animals. Aging in all organisms appears related to reproductive cycle. In animals that reproduce once, near the end of life span, senescence is accelerated once the reproductive act has been completed. In organisms that reproduce several times, senescence is more gradual, beginning during the reproductive 
phase and continuing until death. A major manifestation of senescence in mammals is the loss of lean body mass, and this is often accompanied by increases in fat and body water. As part of this process, muscle tissue is steadily lost through out adult life; thus, older individuals are often weaker and less able to exert themselves physically. As lean body mass decreases, the basal metabolic rate also decreases. Other significant changes take place in the connective tissues. Collagen, a fibrous protein found in bones, skin and tendons, is converted to a sturdier, insoluble form. As the animal ages, the production of new collagen ceases, so that connective tissue consists increasingly of the stiffer, insoluble form. This increased stiffness reduces the permeability of connective tissue to nutrients, hormones, and other substances, and contributes to reduced elasticity in the skin, causing wrinkle formation and increased skin fragility. Similar changes occur in elastin, another fibrous protein found in the walls of blood vessels. Stiffening of the elastin increases the workload on the heart. Changes in nervous system are also marked as are declining proliferative capacity of reproductive cells.

So changes during senescence are occurring at many levels and in many tissues. There is however a consensus amongst different schools of thought which view the concept of biological aging as a failure of the organism to maintain homeostasis (Holliday, 1992).

\section{Theories of Aging}

Many theories have been put forward to explain the above changes. They can be broken down into two classes based on "intrinsic" or "intrinsic" factors. The basis for intrinsic theories is that the series of biological events that constitute the life cycle are programmed by intrinsic factors. This means that aging is predetermined from birth, through puberty, and finally to senescence and death. This theory however has not lent itself well to development of testable hypothesis (Sacher and Truco, 1962). Sacher and Truco compared life tables from inbred and 
outbred animals maintained under uniform conditions. Inbred lines of animals that have identical genetic make up would be expected to have extremely compact life tables. In contrast, there was only slight compacting showing that aging is not completely predestined. In contrast, the extrinsic theories of aging are current and postulate a role for extrinsic factors in the aging process. According to this, age related deterioration is primarily related to structural and functional modifications of cellular constituents. There are four main theories. These are interrelated and implicate free radicals, glycation reaction and/ or Maillard reactions as a causative factor in the aging process.

\section{The Free Radical Theory of Aging}

This widely accepted theory of aging states that unrepaired accumulated cellular damage, caused by free radicals generated by on-going normal metabolism and contributed to by environmental sources, is the basis of aging (Herman, 1956). Free radicals are defined as atoms or molecules that are reactive due to an unpaired or odd electron in an outer orbit (Del Maestro, 1980). This causes the free radical reactions proceed randomly by chain reaction. The most important factor implicating free radicals in the aging process is the fact that under normal physiological conditions, the majority of these free radicals are generated endogenously from impaired $\mathrm{O}_{2}$ molecules by- products of the mitochondrial electron transport reactions involved in energy production. This inherent nature and absolute oxygen requirement for biological systems makes it extremely difficult to eliminate the possibility that free radicals play causal role in aging process ( Halliwell and Gutterridge, 1984). The major cellular sources of free radicals are mitochondria, microsomes, and peroxisomes but other sources too are widespread (Masters,1994). These include intracellular enzyme reactions formed by oxidases,

dehydrogenases and oxygenases and extra cellular sources of oxidant species form glycation and 
maillard reactions (Kristal and Yu, 1992). Nitric oxide synthase (Boje and Arora, 1992) and lipid peroxidation processes (Kristal et al., 1996) also show evidence of the reactive species. Simple electron transfer, to the formation of the superoxide radical converts an estimated 1-2\% of mitochondrial oxygen consumption. It has been estimated that a single cell in a living organism may be exposed to $10^{10}$ molecules of superoxide radical per day. This would mean that a broiler from 0 to 49 days of age would produce 2 to $5 \mathrm{gm}$ of $\mathrm{O}^{*}$ radical.

This theory is meritorious for it provides with both a conceptual base and the experimental opportunities necessary to explain the biological basis of senescence and diseases. The basic knowledge of the mechanisms of formation of these radicals has been extensively reviewed (Halliwell and Gutteridge, 1985). The major radicals are:

\section{A. SUPEROXIDE ANION RADICALS (O를}

A number of cell components are able to perform the monovalent reduction of molecular oxygen i.e., to produce $\mathrm{O}_{2}{ }^{*}$. radicals. Amongst others, these include enzymes like xanthine oxidase, aldehyde oxidase, various dehydrogenases, cytochome P-450, etc. In addition, the autoxidation of reduced flavins, hydrochinones, reduced ferrodoxine, reduced glutathione, reduced hemproteins, and catecholamines leads also to the formation of $\mathrm{O}_{2} *$ radicals. Mitochondrial ubiquinone is considered important because this is involved in the overall pathway of oxygen consumption, i.e. it may transform a given portion of the consumed oxygen into $\mathrm{O}_{2} *$ radicals. These radicals are relatively long-living reductive agents (electron donors) and move to a certain distance from their site of their formation. They can be dismutated into $\mathrm{H} 2 \mathrm{O} 2$ and this process is speeded by about 104 times by the enzyme superoxide dismutase(SOD). Since the $\mathrm{O}_{2} *$ radicals have generally been considered as harmful agents, SOD has gained the glory of being an antioxidant agent ever since its discovery (Beyer et al., 1991). 


\section{B. HYDEROGEN PEROXIDE}

Both the spontaneous and SOD-induced dismutation of the $\mathrm{O}_{2} *$ radicals lead to production of $\mathrm{H}_{2} \mathrm{O}_{2}$. Though this is stable and less harmful than the $\mathrm{O}_{2} *$ radicals, it can diffuse through barriers like cell membrane and reach long distance from its site of production. It has been demonstrated that sulfur-containing organic compounds can easily be oxidized in vitro by $\mathrm{H}_{2} \mathrm{O}_{2}$ but in vivo the concentration is kept rather low and a rather direct oxidation can occur only rarely. $\mathrm{H}_{2} \mathrm{O}_{2}$ is also dangerous because it can combine with transition metals like iron, copper, etc, through a process called heterolysis, and result in production of $\mathrm{OH}^{*}$ free radicals. This process is called the Fenton reaction (Fenton, 1894). The two enzymes that act as defense against the accumulation of $\mathrm{H}_{2} \mathrm{O}_{2}$ in the cells and tissues are catalase (CA) and glutathione peroxidase(GPO). However, there is big difference in the activity of CA of various tissues and it is not able to eliminate all the $\mathrm{H} 2 \mathrm{O} 2$ since its $\mathrm{Km}$ value is relatively high (Goldstein, 1968). The activity of GPO also may not be fully sufficient because it requires glutathione as substrate and this is also required, as a substrate, for a great number of other pathways. Thus it is a rate limiting in the "purification" of the cells from peroxides and a certain flux of $\mathrm{H}_{2} \mathrm{O}_{2}$ is always present in the cells(Chance et al., 1979). An important observation has been made by Cutler, 1985 who found that $\mathrm{H}_{2} \mathrm{O}_{2}$ yield of tissues was found to be inversely proportional to the longevity of tissues.

\section{The Fenton Reaction and the $\mathrm{OH}^{*}$ Free Radicals}

The key to understanding of free radical story is the further fate of that fraction of $\mathrm{H}_{2} \mathrm{O}_{2}$ that is neither eliminated by CA or by GPO or other peroxidases. This freely distributed $\mathrm{H}_{2} \mathrm{O}_{2}$ which is always present in all living systems may participate in various reactions. One of the effects can be direct lipid peroxidation (Donato and Sohal, 1981). However, most important is 
the reaction of $\mathrm{H}_{2} \mathrm{O}_{2}$ with transition metals like $\mathrm{Fe}^{2+}$. This reaction called Fenton reaction, result in the production of $\mathrm{OH}^{*}$ free radicals. The $\mathrm{OH}^{*}$ free radicals formed react very quickly with the rest of $\mathrm{Fe}$ if there are no reactive molecules in the environment. It has been shown in vivo that $\mathrm{OH}^{*}$ radicals are able to attack the amino acids and proteins very efficiently even under mild chemical conditions. Furthermore, rapid aging of young rats could be achieved by increasing the $\mathrm{Fe}^{2+}$ content of brain by injecting iron solutions into the cerebrospinal fluid(CSF) (Nagy et al., 1985). Due to the reactivity of $\mathrm{OH}^{*}$ radicals, a number of molecular alterations can take place in the living system. These have been reviewed by Walling, 1975; Shock et al., 1963 and Stubbe, 1989.

\section{The Glycation Theory of Aging}

This is an expanded version of collagen "cross linking" theory of aging, based on the cross-linking of numerous proteins by modified glucose residues. These cross-links impair both cell and tissue function, and thus lead to age-associated deterioration (Cerami, 1991).

\section{The Maillard Reaction Theory of Aging}

The Maillard reaction is a series of complex process that include initiation , propagation, and termination processes similar to those seen in free radical reactions . Any compound containing an alpha-hydroxy aldo or keto group reacting with epsilon group of amino acids may initiate Maillard reactions. This results in formation of Amadori products via a Schiff base resulting from a condensation reaction between amino groups of protein and aldo or keto moieties of reducing sugars. The Amadori group can degrade further. These propagation processes, including fragmentation's and cross-linking, eventually lead to the advanced Maillard products termed advanced glycosylation end products (AGE's) (Monnier, and Cerami,1981). Crosslinks may be classified into two major groups: those mediated by the enzyme lysyl 
oxidase(Reiser et al., 1992) and those derived from the nonenzymatic addition of glucose adduct (Baynes and Monnier, 1989). In the enzymatic collagen crosslinks, a crosslink begins with lysyl oxidase and oxidative deamination of certain lysine and hydroxylysine residues. The aldehyde moieties formed undergoes further reactions with each other or lysine, hydroxylysine and histidine residues to form a series of di, tri and tetrafunctional crosslinks with collagen (Robins, 1982). In contrast, the nonenzymatic reactions begin between glucose and proteins, collectively known as Maillard reactions. This triggers a series of chemical reaction that ultimately leads to formation and accumulation of irreversible crosslinks. In the beginning, an aldehyde group $(\mathrm{CHO})$ of glucose and an amino group $\left(\mathrm{NH}_{2}\right)$ of a protein are attracted to each other. Since this is an unstable combination it rearranges to a stable, but reversible, substance known as Amadori products. These Amadori products over time combine with various forms of molecules to form irreversible structures called advanced glycosylation end products (AGE's) ((Monnier, and Cerami, 1981). In some tissues and species, aging is associated with reaction products of dysfunctional enzymatic crosslinks and unmodified residues (Yamauchi et al., 1987) but in many tissues, generation of mature crosslinks tend to plateau with age, and do not increase linearly. This suggests that they are unlikely to account for progressive physiochemical changes with age. In contrast, in virtually all tissue studied, there is accumulation of nonenzymatically mediated collagen crosslinks derived from glucose adducts and which increase age. This results in alteration in mechanical properties, solubility, ligand binding and conformation of collagen (Reiser, 1991).Recent theories have suggested that nonenzymatic glycation reactions play a key role in the aging, either alone or in combination with other aging process, such as free radical generation. Such process may have an effect on gene expression during aging (Sohal and Allen, 1990). 


\section{The Free Radical- Glycation/ Maillard Reaction Theory of Aging}

The new theory (Kristal, and $\mathrm{Yu}, 1992$ ) is based on the prediction that age related deterioration is produced by the sum of the damage induced by free radicals, by glycation and other Maillard reactions and their interplay. This hybrid theory has a distinct advantage that the strong points of the individual theories are reinforced since the synergistic efforts potentially increase damage induced by either single arm of the pathway. A scheme for possible synergistic interactions of free radicals, glycation and Maillard reactions in the aging and pathological processes. (Kristal and $\mathrm{Yu}, 1992)$ has been reviewed.

\section{Birds as animal models of aging}

Three logic principles for using animal models are widely quoted( Holmes and Austad, 1994). These are: (1) specificity, or the ability to address specific questions directly; (2) generality, or usefulness in assessing the scope of specific research findings among species; and (3) feasibility, or the logistic ease and cost-effectiveness associated with the use of particular species or strains compatible with either criterion (1) or (2). Specificity means that a given animal model exhibits a trait of particular importance. Since all animals age it could be argued that any species would satisfy the criterion. Currently, there is preponderance of laboratory rodent models in aging research. However, there are differences and problems reported by many workers. Normal human fibroblast lines do not spontaneously transform into immortalized lines in culture, whereas fibroblasts from rodents invariably do (Hayflick, 1997; Martin, 1997). Human cell lines may have quantitatively distinct mechanisms controlling proliferative homeostasis. Also, it has been shown ( Ku and Sohal, 1993) that birds produce fewer free 
oxygen radicals for a given level of oxygen metabolism than do mammals. Hence, there is a possibility that birds have a qualitatively different free radical generating or antioxidant systems than do shorter-lived homiotherms.

The second criterion concerning whether findings of one species are applicable to others is a central question in gerontology today. Such assessment requires a thorough knowledge of the evolutionary relationship between extant animal models and other target species such as humans (Austad, 1993).

The third criterion, that of feasibility means that, an animal model should be as inexpensive, readily available, and as well characterized with respect to husbandry, physiology, and pathology as possible. Overall, researchers working with birds argue that since they age much more slowly than mammals, specific insights into mechanisms of retarded aging may be achieved.

The conventional view was that animals in nature die before they exhibit significant aging( Brokin and Miller, 1974; Comfort, 1979; Williams, 1992). This has been demonstrated to be false for mammals (Promislov, 1991), and is probably false for birds as well. A number of ornithologists have reported visible signs of age-related pathologies in individuals in their study populations (Calder, 1990; Finch, 1990). Birds clearly are longer lived and age more slowly than comparatively sized mammals, both in nature and captivity. Maximum longevity of wild birds average 1.7 times greater than those of captive mammals, and captive birds are nearly three times as long-lived as captive mammals.(Lindstedt and Calder, 1976; Austad and Fischer, 1991). Mortality rates also appeared to be slower for birds than mammals. Although birds on the whole are long- lived relative to mammals of similar body size, with life span generally correlated with body mass, certain bird groups are extremely short or long- lived. Maximum captive life spans for individual Scarlet Macaws, has been documented to be over 90 years (Etchepare, 1990) or 
more than four times the longevity predicted from the body size of this species (Holmes et al., 1993). The most long-lived birds of all are the hummingbirds, which include the smallest bird species( some less than $5 \mathrm{~g}$ ) with the highest metabolic rates. The captive record for this bird is a life span of 14 years for a Planalto Hermit (Calder, 1990). At the other end, the shortest lived, most rapidly reproducing and senescing bird species of any size documented to date is the Common Quail, Coturnix, with a mean life span of one year in the wild ( Ottinger et al., 1983; Puigcerver et al., 1992). Even this 90-g bird, however ages much more slowly in the lab than an equivalent sized rodent. Thus bird longevity is consistent with the evolutionary theory of aging, which predicts that, other things being equal, species subject to low level of extrinsic (i.e. nonage-related) mortality will evolve to age more slowly than species subject to high mortality rates. Since flight affords protection against extrinsic mortality due to predation or accident, aging theory predicts that most birds should age more slowly than mammals ( Edney and Gill, 1967; Austad and Fischer, 1991).

There are indications that free radical production in the bird (Red-tailed Hawk and chicken) heterophils was significantly lower than that in analogous bovine neutrophils (Conlon et al., 1991). In a more recent study (Ku and Sohal, 1993), it was found that mitochondrial generation of free radicals and peroxide was lower in pigeons, and that pigeons had higher antioxidant activities.

Thus if one considers an overview of things, birds offer manifold advantages as animal models for biogerontology. Their chief features relative to aging research are many (Holmes and Austad, 1994). These traits include

1. Metabolic rates as much as 2 to 2.5 times as high as those of mammals of similar body sizes do. 
2. Blood sugar levels typically 2 to 4 times as high as those of mammals do.

3. An elevated body temperature (about $3^{0}$ higher than mammals)

These higher metabolic rates coupled with the extreme longevity of many avian species result in much greater lifetime expenditure per unit mass by birds than mammals. It is also assumed that the lifetime energy expenditure correlates with an organism's cumulative exposure to potentially damaging oxygen free radicals (Pierrefiche and Laborit, 1995). The elevated avian metabolic rate should expose the birds to a higher level of oxygen free radical production, and consequently, accelerated tissue damage, while the hyperglycemia and elevated body temperature should accelerate formation of advanced Maillard products, also thought to be involved in aging related tissue degeneration. (Sell and Monnier, 1991; Dyer et al., 1991a, 1991b and Nagaraj et al., 1996). It appears that birds have evolved mechanisms to limit the damages caused by these degenerative reactions.

\section{Pentosidine: An aging marker in birds?}

Pentosidine was first isolated by Sell and Monnier (1989) and is most widely described Maillard structure. It is an imidiazopyridium compound composed of single lysine and arginine moieties crosslinked by a pentose. The major in vivo carbohydrate source leading to pentosidine formation is not known. However, oxidation reactions are required (Baynes, 1991). Since it is acid stable, it has been possible to identify it in numerous collagenous and non-collagenous tissue and is shown to increase with age in normal tissue in many species studied (Sell et al., 1996). Though it may not predict the assessment of cumulative damage to proteins by nonenzymatic reactions of the Maillard reaction, it's usefulness as aging marker has been reported (Iqbal et al, 1998). 


\section{Uric Acid: An Antioxidant Evaluation}

The ability of uric acid to exert antioxidant ability has been known for several decades but it was first proposed to be an important biological antioxidant in 1981 (Ames et al., 1981). Uric acid is produced by the oxidation of hypoxanthine and xanthine by xanthine oxidase and dehydrogenase enzymes. In most species, another enzyme, urate oxidase, converts it into allantoin, which is further converted to allantoate and then gloxylate plus urea. However, humans and other primates lack urate oxidase: the gene is present in the human genome, but a stop codon in one of the exons is present and the defective gene appears not to be transcribed.(Yeldandi et al., 1990) Hence uric acid accumulates in human body fluids to concentrations in the range of 0.2-0.4 $\mathrm{mM}$ and is excreted in the urine. At physiological $\mathrm{pH}$ almost all uric acid is ionized to urate, bearing a single negative charge. Urate is limited solubility in water; excess production in vivo can lead to crystallization out of solution, as in gout, which is often treated with the xanthine dehydrogenase/ oxidase inhibitor allopurinol.

Antioxidant properties of uric acid have been studied in both in vitro and in vivo. Uric acid is a powerful quencher/and or scavenger of singlet $\mathrm{O}_{2}$. Sources of singlet $\mathrm{O}_{2}$ in vivo include photochemical reactions, reactions of $\mathrm{O}_{3}$ with some biological molecules, and peroxyl radical termination reactions in the later stage of lipid peroxidation ( Sies and Murphy, 1991). There is as yet no clear evidences that urate offers protection against singlet $\mathrm{O}_{2}$ in vivo. Many papers have also shown that urate inhibits lipid peroxidation ( Esterbauer et al 1989; Smith and Lawing, 1983; Niki et al., 1986; Green et al, 1986).. Often, this is due to chelation of "catalytic" iron or copper ions. The allantoin concentration in human plasma rises during oxidative stress, e.g. in patients with chronic inflammatory joint disease or with iron overload disease, consistent with the concept that allantoin arises by attack of reactive oxygen species upon urate (Grootveld and Halliwell (1982) They also suggest that measurement of allantoin and other oxidation products 
of urate could be used as evidence for generation of reactive oxygen species and their attack upon urate in vivo. It has also been shown that the maximum life-span potentials of several mammalian species are correlated with their urate levels in serum and brain, corrected for metabolic rate( Cutler 1984). Plasma uric acid concentrations increased exponentially with respect to time after intense exercise in horses, indicating a rapid increase in the rate of purine degradation. Authors reason that intense exercise causes an increase in the plasma antioxidant capacity that in the horse is mainly caused by the increase in the plasma uric acid concentration (Rasanen et al 1996). On the other hand, raised serum uric acid levels are associated with conditions at high risk for coronary heart disease in human subjects (Russo et al., 1996).

Uric acid level does not seem to be influenced by diet restriction in turkey pullets (Cason and Teetor, 1994). Uric acid level was lowered in Ascitis birds at 3 weeks compared with control birds (Enkvetchakul et al 1993). In guinea pig, uric acid has been shown to be ineffective in checking lipid peroxidation.

\section{$\underline{\text { Uric Acid Manipulation }}$}

The fact that uric acid could be manipulated has come from the observations in the treatment of the pathologic condition, gout in humans. Gout is a disease-characterized biochemically as a disorder of uric acid metabolism and clinically by hyperuricemia and recurrent attacks of acute arthritis. Treatment of the hyperuricemia of gout depends upon lowering blood uric acid levels and many drugs such as allopurinol, probenicid or sulfinapyroge have been used. Allopurinol reduces serum urate level through a competitive inhibition of uric acid synthesis. This is accomplished by inhibiting xanthine oxidase, the enzyme involved in the metabolism of hypoxanthine and xanthine to uric acid. After enzyme inhibition the urinary concentration of uric acid is greatly reduced and a simultaneous increase in the excretion of the more soluble compounds xanthine and hypoxanthine occurs. Allopurinol is metabolized by 
xanthine oxidase to form the oxypurinol. Oxypurinol itself is not administered because it is not absorbed as well is allopurinol (Knox Van Dyke, 1986). Administration of allopurinol generally results in a fall in both the serum and urine levels in 2-3 days. By varying the dose the percentage fall of uric acid can be manipulated. However, reports of use of allopurinol and its dosage in farm or companion animals are limited. It has been used in thoroughbred horses at a dose rate of 30mg/Kg-body weight, orally. It was suggested by Wexler and McMurtry (1981) that allopurinol provides protective effects in an isoproterenol induced myocardial infarction in rats. Their data suggested that allopurinol had anabolic effects on protein metabolism and this accounted for its cardioprotective characteristics. Czarnecki et al., (1986) evaluated the role of allopurinol as a cardioprotectant in ethanol induced cardiomyopathy in turkeys.

\section{Diet Restriction and Aging}

Among the many anti-aging measures tried so far, the most effective mean discovered is the caloric or diet restriction. Extensive gerontological research within the last two decades have confirmed and amplified McCay's original finding that restricting the food intake of laboratory rodents extends their mean and maximum life span (Yu et al 1982; Berg and Simms, 1960). The term's caloric restriction, diet restriction or feed restrictions all reflect the reduced food intake of experimental animals compared to that consumed by the control. Dietary restriction in addition to extending life span, also alters physiological parameters by modulating most age-associated functional decline as well as by delaying the onset and/ or retarding the progression of a large number of age-related diseases (Everitt, A V and Cavanagh, L.M. 1965). Now there is an overwhelming body of data firmly establishing DR as the most effective known means of retarding aging process in mammals. One critical reason for the many intensive investigations is that the DR as an experimental probe meets three critical criteria for a model system- 
reproducibility, effectiveness and inherent simplicity (Weindruch and Walford, 1988; Masora, 1989).

\section{Mechanism of the Action of DR}

The mechanism remains undefined though many hypothesis have been put forward. These in brief, are

\section{The Growth and Development Hypothesis}

The states that reduced size and stunted growth of DR animals is the cause of increased longevity (McCay et al, 1939) was argued against by many (Ross, 1972, Nolen, 1972, and Weindruch and Walford, 1982. All more or less showed that restriction, started before or after the growth phase, is equally effective. Together these results suggest that effects on growth and development are neither necessary nor sufficient to explain the effects of DR, but they may serve to augment other effects.

\section{The Adiposity Hypothesis}

Since reduced longevity in man and adiposity were correlated, it was the natural tendency of workers to extrapolate that to animals since the DR animals were lean. However, closer looks at ad-libitum fed rats (Bertrand et al., 1980) disapproved this notion. In fact, in restricted animals there was positive correlation existing between body fat and longevity. Similar conclusions have been reached by other workers ( Stuchlikova et al., 1975 and Harrison et al., 1984) who came too similar findings.

\section{The Glucocorticoid Cascade Hypothesis}

The basic concept of this hypothesis is that elevated glucocorticoids levels lead to chronic stress. Several studies lend support to this and have been confirmed by experimentally induced accelerated aging. If this theory is true, one can say that glucocorticoid levels will be higher in $a d$ 
libitum fed animals than diet restricted animals. Although further studies are needed, results from the DR studies (Sabtino et al 1991) suggest that the major role of glucocorticoid in aging is not as an accelerator of the aging process.

\section{DIET RESTRICTION : HOW GOOD A MODULATOR OF FREE RADICAL}

\section{METABOLISM?}

Recent studies have shown that DR can indeed modulate free radical metabolism. Primary work reports have concentrated in three areas

\section{Attenuation of Free Radical Production and Lipid Peroxidation by DR}

The major sources of free radical productions are mitochondria and microsomes. The ability of mitochondria, for example to generate free radicals can be seen by the fact that $1-2 \%$ of mitochondrial oxygen consumption is converted to the formation of superoxide by a single electron transport, due to the reduction of ubiquinone Under normal conditions, the amount of superoxide generated by a mitochondrion, has been estimated to be as high as $10^{7}$ superoxide radicals per day. Because of this they become prime targets of free radical attack that can potentially compromise their function. Although free radical production does not increase per se the damage induced, e.g., lipid peroxidation, is detected very widely. The production of superoxide, hydroxyl radicals, reactive $\mathrm{H}_{2} \mathrm{O}$, and lipid peroxidation of mitochondrial and microsomal membranes are all attenuated by DR. This could play a major role in the increased membrane rigidity.

\section{Antioxidant Defense Systems}

Since free radicals destroy cellular constituents, it is essential that defense measures exist to protect these components by neutralizing free radicals. The beneficial effects of such mechanisms has been documented (Cutler, 1984). The age related deterioration of cystolic 
antioxidative defense systems can be countered by DR.. More recent data reported by several laboratories ( Laganiere and Yu., 1984) substantiated the earlier studies and expanded further, thus putting the antiperoxidative action of dietary modulation on firmer basis.

\section{Detoxification and Elimination}

It is now reported that that there is potential ability of lipid peroxidation products such as malonaldehyde and 4-hydroxynonenal to damage biological molecules (e.g., proteins, DNA). This has been well accepted. Since the production of these endogenous by-products cannnot is completely prevented, it is essential that be removed or otherwise detoxifies them. Unfortunately, it was discovered that process that eliminates these potential cytotoxic compound also decreases with ages. This explains the accumulation of these by-products leading to formation of lipofuscin pigments that occur during aging. There is reduced accumulation of age pigmentation in DR animals( Chou et al., 1991).

\section{OXIDATIVE STRESS AND CELLULAR CHEMILUMINESCENCE}

Life in oxygen has led to the evolution of biochemical adaptations that exploit the reactivity of active oxygen species. Oxidative stress is a general term used to describe a state of change caused by reactive oxygen species. This damage can affect a specific molecule or the entire organism. All the different sources of ROS can cause oxidative damage to an organism. Most of the ROS come from endogenous sources as by-products of normal and essential reactions, such as energy generation from mitochondria or the detoxification reactions involving the liver cytochome P-450 system. Exogenous sources include bacterial, fungal or viral diseases.

\section{Detection of production of ROS by Luminol Chemiluminescence}

In the 1960s several soviet investigators reported the phenomenon of "dark chemiluminescence (CL)" from living tissues (Baremboin et al., 1969). It was called dark because light emission levels were too weak to be perceived by the unaided eye. The source was 
attributed to the oxidation of lipids and was enhanced by reagents such as luminol. Boveris et al., (1981) concluded that CL is caused by lipid peroxidation and have concluded the sources of emission to triplet ground state $\left(3 \mathrm{O}_{2}\right)$ and to relaxation to ground state of excited state carbonyl groups. Howes and Steel (1971) too supported the view that ${ }^{1} \mathrm{O}_{2}$ was involved in CL. In 1972, Allen et al found CL to be generated by human polymorphonuclear leukocytes (PMN) stimulated by bacteria. Hoever, CL was at a disadvantage because of low photon yield a large number of cells were required. This problem was solved by Allen and Loose (1976) who used luminol (5amino-2,3-dihydro-1,4-phthalazinediane) to enhance CL associated with the oxidative burst of PMN. Baldridge and Gerard (1933) were the first to show that PMN enhance their oxygen consumption when stimulated to phagocytosis by bacteria. A quarter of century later, Iyer et al., (1961) and later on Cheson et al (1978) and Harrison and Shultz (1978) found that stimulated PMN could produce hydrogen peroxide (H2O2), superoxide (O2-) and hypochlorus acid (HOCl). Now luminol dependent chemiluminescence is observed during the burst of macrophages and neutrophils. In order to yield light, luminol has to undergo a two-electron oxidation and form an unstable endoperoxide. This luminol endoperoxide decomposes to an excited state, 3aminophthalic acid, which relaxes to the ground state by emitting photons. In most cases of luminol chemiexcitation in biologic systems, $\mathrm{O}_{2} *$ is a key intermediate. 


\title{
Chapter 3 \\ Study 1
}

\section{Accelerated Tissue Aging and Increased Oxidative Stress in Broiler Chickens fed}

\section{Allopurinol}

\begin{abstract}
Uric acid has been hypothesized as one of the most important antioxidants in limiting the accumulation of advanced glycolated endproducts (AGEs) in broiler breeder hens. This study was designed to quantitatively manipulate the plasma uric acid concentrations using hemin and allopurinol and determine its effect on skin pentosidine (Ps), shear force value (SF) of Pectoralis major muscle, plasma glucose, body and breast weight, and chemiluminescence (CL) induced oxidative stress in broiler chickens. The scavenging capacity, in terms of reduced generation of superoxide and hydroxyl free radicals, of allopurinol was determined by electron spin resonance (ESR) spectroscopy. In a preliminary trial $(\mathrm{n}=60)$, feeding allopurinol $(10 \mathrm{mg} / \mathrm{Kg}$ body weight) decreased plasma uric acid by $57 \%$ at $10 \mathrm{~d}$ post-hatch. On the other hand, hemin $(10 \mathrm{mg} / \mathrm{Kg}$ body weight) increased its concentrations $20 \%$. In a second study, lasting $10 \mathrm{wk}$, broiler chicks $(\mathrm{n}=90)$ were randomly assigned to two groups at 12 wk of age: ad libitum (AL) and diet restricted (DR), with three treatments (control, allopurinol or hemin fed). Allopurinol decreased plasma uric acid, ranging from $26 \%$ to $74 \%$, with the most pronounced effect at wk 22 . Hemin increased plasma uric acid concentrations between 11 and 14\%. Skin pentosidine levels increased $(\mathrm{P}<0.05)$ in the allopurinol fed birds, in both DR and AL, at 22 wk of age and in hemin fed birds at wk 22. Hemin increased $(\mathrm{P}<0.05)$ the chemiluminescence dependent oxidative stress, for DR (22 wk) and AL (16 and $22 \mathrm{wk})$. Allopurinol elevated $(\mathrm{P}<0.05)$ the oxidative stress in the AL fed birds at wk 22, reduced $(\mathrm{P}<0.05)$ the body and breast weight in both AL and DR fed birds at16 and 22 wk of age, and markedly increased $(\mathrm{p}<0.001)$ shear values. In conclusion, the
\end{abstract}


reduction in uric acid concentration was associated with an increase in the level of oxidative stress, which can be linked to the increase in tissue Ps, thus advancing the decline in meat tenderness.

Keywords: uric acid, allopurinol, hemin, pentosidine, oxidative stress, shear force

\section{Introduction}

Most avian species are significantly longer-lived than mammals of comparable body size (Lindstedt and Calde, 1976). The maximum longevity in birds has been known to range from 4 years in blue jays (Cyanocitta cristata) to 64 years in the Macaw (Ara macao). The longevity of birds is somewhat surprising, since they exhibit many traits that should render them more susceptible to the degenerative process of aging. These traits have been reviewed (Holmes and Austad, 1995; Beuchat and Chong, 1997) and include: (1) metabolic rates as much as 2 to 2.5 times as those of mammals of similar body sizes. (2) blood sugar levels typically 2 to 6 times higher than those of mammals, and (3) body temperatures about $3^{\circ} \mathrm{C}$ higher than mammals. All these factors expose them to a higher rate of free oxygen radical production and accelerated formation of advanced Maillard products. Without special protective mechanisms against the potential for damage, birds should be comparatively short lived and age more rapidly than mammals. However, it has been reported that avian species have higher levels of circulating antioxidant (alpha tocopherols, carotenoids and uric acids) as compared to the comparable size

mammals (Ames et al., 1981; Cutler, 1984a, 1984b). It appears that birds have evolved mechanisms to limit the damage caused by these degenerative changes.

Uric acid is one of the circulating antioxidants that demonstrate a positive correlation with maximum life span across species (Ames et al., 1981; Schreiber et al., 1986). It has been proposed as a potent scavenger of free radicals in human and many animal tissues (Hellsten et 
al., 1997). Humans, the most long-lived among primates, have comparatively high levels of uric acid because they lack uricase, the terminal degradative enzyme present in monkeys and other mammals (Ames et al., 1981; Schreiber et al., 1986). In support of this concept, the lower levels of uric acid in macaques ( 3 fold as compared to humans) correlates with a shorter life span as compared to humans (Short et al., 1997). It has been demonstrated that urate, in vitro, has the ability to scavenge peroxides, hydroxyl radical species and hypochlorus acid and supply 30-65 \% of the peroxyl radical scavenging ability (Becker, 1993; Hellsten et al., 1997). Uric acid is ubiquitous and it has been shown to decline with an increase in reperfusion injury in humans following myocardial infarction (Parmley et al., 1992). For this reason, it has been proposed that lower tissue concentrations of the glycoxidation product, pentosidine (Ps) in birds as compared to mammals are due to a more efficacious avian antioxidant system which includes concentrations of uric acid, approximately two fold greater than that measured in humans (Bishop et al., 1992; Shapiro et al., 1997; Iqbal et al., 1998, 1999). Ps is a tissue crosslink that forms within the matrix of a protein. Though there are numerous antioxidants present in the body system of birds, the role of uric acid has not been established.

In the current study, the role of uric acid as an antioxidant, in chickens, was evaluated. The specific objectives were to determine the effects of allopurinol and hemin on uric acid levels in broiler chickens and on the accumulation of Ps and shear values (SV) of pectoralis major muscle.

\section{Materials and Methods}

Birds and Management

The purpose of the first study was to establish the dose rate of allopurinol and hemin required to manipulate concentrations of plasma uric acid in broiler chicks. Allopurinol is a 
structural analogue of the natural purine base, hypoxanthine and is a potent inhibitor of xanthine oxidase, the enzyme that converts hypoxanthine to xanthine and of xanthine to uric acid (Bartges et al., 1997). Hemin, on the other hand, increases the concentration of uric acid (Miller et al., 1993). We also wanted to determine the scavenging capacity of allopurinol, and its derivative oxypurinol, in terms of reduced generation of superoxide and hydroxyl free radical, as determined by electron spin resonance (ESR) spectroscopy measurements.

Broiler chicks ( $\mathrm{n}=90$; Ross x Ross; mixed sex) approximately 6 weeks of age were obtained from Ross Breeders (Ross Breeders, Huntsville, AL 35805) and maintained under standard husbandry practices. These included recommended brooders and temperatures, bell drinkers and pan feeders. Specifications for space, temperature, light and husbandry were adhered to (Ross Breeders, 1996). At eight wk of age 50 broilers were divided into five groups: control, allopurinol fed $(5 \mathrm{mg} / \mathrm{kg}$ and10 $\mathrm{mg} / \mathrm{kg} \mathrm{BW})$ and hemin fed $(5 \mathrm{mg} / \mathrm{kg}$ and10 $\mathrm{mg} / \mathrm{kg} \mathrm{BW})$. Allopurinol and hemin supplemented feed was prepared every week based on the weight of the birds the previous wk. Blood was sampled for plasma uric acid determination at d 3 and 10 . Determination of hydroxyl and superoxide radical production was by ESR.

After the determination of appropriate dose rate the main trial started when birds were 12 wk old. The birds were divided into two groups, diet Restricted (DR) and ad libitum (AL) and with three treatments within each group (Control, Allopurinol Fed, and Hemin Fed). The diet restricted birds were fed with a limited allowance diet (Table 1). Birds were killed at 4 and 10 wk after the onset of the trial.

\section{Electron Spin Resonance (ESR) Measurement}

Electron Spin Resonance (ESR) spin trapping was used to detect short-lived free radical intermediates (Shi et al., 1997). This technique involves addition type reaction of short lived 
radicals with a diamagnetic compound (spin trap) to form a relatively long lived free radical product, also called spin adduct, which can be studied by ESR. The intensity of the spin adduct signal corresponds to the amount of short-lived radicals trapped.

All ESR measurements were made using a Varian E4 spectrometer and a flat cell assembly. Hyperfine splitting was measured to $0.1 \mathrm{G}$ directly from magnetic field separations using potassium tetraperoxochromate $\left(\mathrm{K}_{3} \mathrm{CrO}_{8}\right)$ and 1,1 diphenyl 2 picrylhydrazyl (DPPH) as standards. The relative radical concentration was estimated by multiplying half of the peak height by multiplying by $\left(\Delta \mathrm{H}_{\mathrm{pp}}\right)^{2}$ (Shi et al., 1997). $\left(\Delta \mathrm{H}_{\mathrm{pp}}\right)^{2}$ represents peak to peak width. Reactants were mixed in test tubes in total final volume of $0.50 \mathrm{ml}$. The reaction mixture was than transferred to a flat cell for ESR measurements.

\section{Pentosidine (Ps) Determination}

Birds $(n=5)$ from, the second study, were randomly selected from each dietary group, at 16 and 22 wk of age and killed by electrical stunning. Approximately, $\lg$ of skin was removed from the abdominal area, washed with normal saline and stored at $-80^{\circ} \mathrm{C}$ until further use. The collagen digest was first prepared as per protocol described by Monnier et al. (1986) and Sell et al. (1992). Briefly, this technique involves skin preparation (removal of the epidermis and adipose layers and very fine mincing), delipidation in a chloroform-methanol mixture (2:1), and rehydration in $50 \%$ methanol and than hydrolyzing in $6 \mathrm{~N} \mathrm{HCl}$ at $110^{\circ} \mathrm{C}$ for 18 hours, after flushing with nitrogen. The samples were placed into a Speed Vac Centrifuge (Savant Speed Vac AES 2000, Bi-County Boulevard, Farmingdale, NY 11735) and vacuum desiccated. Reconstitution of sample was done with $250 \mu \mathrm{ldd} \mathrm{H}_{2} \mathrm{O}$ and filtered using a Costar@ Spin-X@ centrifuge tube filter (Corning Costar Corporation, Cambridge, MA 02140) 
. Collagen was estimated by the modified Stagmen and Stalder method using a hydroxyproline standard. This method takes into account that hydroxyproline makes up $14 \%$ of the total collagen (Maekawa et al., 1970). The estimation of Ps was done by reverse phase HPLC (Iqbal et al., 1997). One $\mathrm{mg}$ of skin collagen digest in $100 \mu \mathrm{l}$ water/0.01M heptaflurobutyric acid (HFBA) was injected into a $0.46 \times 25 \mathrm{~cm}$ Vydac $218 \mathrm{TP} 104(10 \mu \mathrm{m}) \mathrm{C}-18$ column (Vydac, Hesparia CA 92345) connected to a Waters HPLC (Waters, Milford, MA 01757). The apparatus consisted of two pumps (Waters ${ }^{\mathrm{TM}} 600$ Controller), an auto sampler (Waters ${ }^{\mathrm{TM}} 717$ plus), and a scanning florescence detector (Waters ${ }^{{ }^{\mathrm{TM}}} 474$ plus). Separations were achieved by a linear gradient of $12-42 \%$ acetonitrile from 0 to $25 \mathrm{~min}$ in water and $0.01 \mathrm{M}$ HFBA at flow rate of 1 $\mathrm{ml} / \mathrm{min}$. The Ps peak was monitored by an on line scanning fluorescence detector at excitation wavelength $325 \mathrm{~nm} / \mathrm{emission}$ wavelength $370 \mathrm{~nm}$. Quantitation of Ps was made by comparison with standard curve made by peak areas with a Ps standard (Vincent M. Monnier, Cleveland, OH 44120) injected under identical conditions. A software package (Millennium 2.1), that comes with the equipment, was used for integration of peaks.

\section{Breast Weight, Cooking Time and Shear Value Evaluation}

Birds were electrically stunned and bled using a modified Kosher technique (Iqbal et al., 1997). The pectoralis major muscle was isolated, refrigerated at $4^{0} \mathrm{C}$ for $4 \mathrm{hrs,} \mathrm{vacuum} \mathrm{packed,} \mathrm{and}$ stored at $-20^{\circ} \mathrm{C}$ until further processed. The breast muscle was cooked to an internal temperature of $70^{\circ} \mathrm{C}$ on a Farberware Smokeless Indoor Grill (Model 450N, Farberware, Inc., Bronx, NY 10462). The endpoint internal temperature was monitored with an industrial data logger, equipped with a copper-constant thermocouple (Omega Technologies, Stanford, CT 06907). 
Cooked muscle was cooled to room temperature and refrigerated overnight at $4^{0} \mathrm{C}$. Slices of approximately $1.27 \mathrm{~cm}$ were cut perpendicular to fiber orientation of the muscle. From each sample, 4 to 5 cores were removed from the thickest portion of the cooked muscle. Sheer value (SV) was determined by using an Instron Universal Mechanical Machine Model TM, (Instron Corp., Canton, MA 45419). A Warner- Bratzler Apparatus was attached to a $50 \mathrm{~kg}$ load cell (Model 152050, Daytronic, Miamisburg, $\mathrm{OH}$ 45342) and tests were performed at cross head speed of $127 \mathrm{~mm} / \mathrm{min}$. Output from a LVDT conditioner (Model 9130, Daytronic, Miamisburg, OH 45342) was acquired by a computer equipped with a DT 2805 data acquisition board (Data Translation, Marlboro, MA 01752). Signals were processed with the HP-VEE software package (Hewlett Packard Co., Love Land, Co 80539- 9929).

\section{Uric Acid and Glucose Determination}

Plasma uric acid ( $\mathrm{n}=5$ per treatment group) was determined using Uric Acid Reagent (Procedure No. 685, Sigma Diagnostics, St. Louis, MO 63178) as per the guidelines of the manufacturer. Plasma glucose was measured using a YSI 2700 Select Biochemistry Analyzer as per the guidelines of the manufacturer (YSI, Inc., Akron, OH 45387).

\section{Measurement of Luminol-Based Chemiluminescence (LBCL) Oxidative Stress}

Chemiluminescence is a functional assay to study the release of oxidants from cells or tissues (Van Dyke et al., 1987; Radi et al., 1993). Luminol-Based Chemiluminescence (LBCL) Oxidative Stress was measured as described by Iqbal et al. (1999). One milliliter of blood from 16 and 22 wk old birds (n=5) was suspended in mono-polyresolving medium (ICN 16-980-49) leukocytes were isolated by centrifugation. The total number of leukocytes was counted using a routine hemocytometric technique. To a $3 \mathrm{ml}$ luminometer tube were than added $100 \mu \mathrm{l}$ of leukocytes, $100 \mu \mathrm{l}$ luminol solution, $200 \mu \mathrm{l}$ PBS, and $100 \mu \mathrm{l}$ phorbol myristate acetate (PMA). 
Luminol was incorporated into the reaction cuvettes as an amplifying agent of chemiluminescence to study the oxidative activity. Luminol is first oxidized to an intermediate that subsequently converts to an aminophthalate product with the release of photon $(\sim 425 \mathrm{~nm})$. Luminol reacts with superoxide, nitric oxide, and their reaction product, peroxynitrite. The luminometer tube was placed into a luminometer (Berthold model LB 9505C, D 7547 Wildbad 1, P. O. B. 160 Germany) with the temperature control set at $37^{\circ} \mathrm{C}$. Oxidative activity was determined by measuring the luminescence generated over 20 minutes. Results were reported as counts per minute (CPM). A PC running KINB software, which comes with the luminometer, analyzed the data. Luminescence was corrected for each group based on the number of leukocytes present.

\section{Statistical Analysis}

Data were analyzed by the general linear models procedure (SAS Institute, 1990). The Student-Newman-Keuls Multiple Range test was used to estimate the significance of difference between means.

\section{Results}

Results of first trial demonstrated that at d 10, plasma uric acid decreased $(\mathrm{P}<0.05)$ when allopurinol was fed at the rate of $10 \mathrm{mg} / \mathrm{Kg} \mathrm{BW}$. There was a $57 \%$ decrease in uric acid concentrations compared to controls. In contrast, there was $20 \%$ increase at d 10 in plasma uric acid when hemin, at the rate of $10 \mathrm{mg} / \mathrm{Kg} \mathrm{BW}$, was fed. There was no significant effect of uric acid manipulation at $\mathrm{d} 3$.

Figure 1 shows the effect of $\mathrm{H}_{2} \mathrm{O}_{2}$ on the ${ }^{*} \mathrm{OH}$ generation from a reaction mixture recorded 3 min after reaction initiation from a $\mathrm{pH}$ of 7.4 phosphate buffer containing $1 \mathrm{mM}$ DMPO, $0.1 \mathrm{mM} \mathrm{H} \mathrm{H}_{2}$ and $0.02 \mathrm{mM} \mathrm{Fe}(\mathrm{II})$. The intensity of the * $\mathrm{OH}$ generation decreased 
ninefold when a saturated solution of allopurinol (1b) and oxypurinol (1c) was added. There was approximately $40 \%$ and $30 \%$ reduction in intensity of the ${ }^{*} \mathrm{O}$ radical production with allopurinol and oxypurinol addition, respectively (Figure 2).

\section{Study II}

\section{Plasma Uric Acid and Glucose}

Allopurinol $(\mathrm{P}<0.05)$ reduced plasma concentrations of uric acid, both in AL and DR birds (Figure 3). The reduction ranged from $26 \%$ to $74 \%$, being more pronounced by wk 22 . Uric acid concentration was marginally higher in the AL birds compared to the DR controls at wk 16 although the increase was not significant. Hemin increased uric acid concentrations at wk 16, with an increase of 11 to $16 \%$. At wk 22, there was an increase (14\%) only in the DR group. Glucose concentrations were not $(\mathrm{P}<0.05)$ different nor showed any consistent trend throughout the study (Table 2).

\section{Skin Pentosidine}

Ps concentrations were increased $(\mathrm{P}<0.05)$ in the $\mathrm{AL}$ and $\mathrm{DR}$ allopurinol fed birds at 22 wk of age (Figure 4). There was an increase of $50 \%$ in the DR group and a seven-fold increase in the AL group. However, at wk 16, there was an increase $(\mathrm{P}<0.05)$ only in the DR allopurinol group. There was no consistent response in hemin fed birds. While there was no effect at wk 16 in the AL group Ps could not be detected in the DR group. At wk 22 it was detectable in the DR birds and markedly increased $(\mathrm{P}<0.05)$ in the AL birds.

\section{Chemiluminescence Dependent Oxidative Stress}

Hemin increased the chemiluminescence dependent oxidative stress, $(\mathrm{P}<0.05)$ at $22 \mathrm{wk}$ in both the DR and AL groups and in the AL birds at $16 \mathrm{wk}$. Allopurinol elevated $(\mathrm{P}<0.05)$ the oxidative stress in the AL wk 22 group (Figure 5). Both hemin and allopurinol elevated the total 
leukocyte count, both at 16 and 22 wk. This was much more pronounced $(\mathrm{P}<0.05)$ in hemin fed birds. There was 2.7 and 4.0 fold increase in the Total Leukocyte Count at wk 16 and 22, respectively, in the hemin fed birds (Table 3).

\section{Body and Breast Weight, and Shear Force}

Allopurinol reduced both the body and breast weight, in both groups at both 16 and 22 wk (Table 1). The reduction was more pronounced $(\mathrm{P}<0.001)$ in case of breast weight for all treatment groups except DR, 16 wk group (Figure 6). There was 49\% and $35 \%$ decreased breast weight in the DR and AL birds, respectively. The reduction in body weight was more pronounced at wk 22 (Figure 8). Mortality was $40 \%$ in the allopurinol fed birds during the period of trial, compared to 7 and $13 \%$ in the control and hemin fed birds. Allopurinol fed birds had increased $(\mathrm{P}<0.05)$ shear force values compared with the control birds. There was $88 \%$ and $58 \%$ increase in the DR and AL group at wk 22 (Figure 5). However, there was no significant effect of allopurinol at $16 \mathrm{wk}$. Hemin marginally reduced the shear values at wk 22 , although the effect was not significant. No diet effects were seen for hemin, at either wk 16 or 22.

\section{Discussion}

Previous studies have established that birds have higher concentrations of antioxidants in their bodies and appear more efficient in dealing with the oxidative stress as compared to mammals (Youngman et al., 1992; Yu et al., 1982 and Yu, 1993). Iqbal et al., (1997, 1999) hypothesized that uric acid plays an important role in limiting oxidative stress and subsequent accumulation of advanced glycosylation endproducts (AGEs), such as Ps. The present study deals with the effects of uric acid manipulation on oxidative stress, glycoxidation product, skin pentosidine (Ps) and shear value in broiler chickens. In previous studies dose rates of allopurinol from 2-50 mg/kg have been used in laboratory rats (Klein et al, 1975), $6.5 \mathrm{mg} / \mathrm{kg}$ in dogs, and 
varying dose rates, from 30 to $50 \mathrm{mg} / \mathrm{kg}$, in ethanol fed turkey pullets (Czarnecki et al., 1987). In the present study the administration of allopurinol to broiler chickens was shown to decrease plasma uric acid concentrations. The reduction ranged from $26 \%$ to $74 \%$, being more pronounced with the duration of the treatment, but was unexpectedly associated with an increase in mortality. Results from Study I did not suggest that the dose selected was toxic although the duration of treatment was shorter. The lowering of the uric acid is explained on the basis of allopurinols primary action, inhibition of xanthine oxidase, an enzyme that is involved in the conversion of hypoxanthine to xanthine and xanthine to uric acid. This indicates that broiler chickens are responsive to allopurinol treatment and that the major metabolite of allopurinol, oxypurinol, is probably responsible for the inhibition of xanthine oxidase. A decrease in the uric acid concentration was accompanied by a decrease in the body and breast muscle weight (49\% and $35 \%$ decreased in breast weight) and an increase in tissue aging as evidenced by an increase in shear force values (88\% and 58\% increase) in the DR and AL group, respectively. In human subjects, many conditions result in hyperuricemia (gout, alcoholism, cardiac myopathy, etc) and in the search for appropriate animal models, poultry can also be a valuable tool since the uric acid levels can be manipulated.

Hemin, $(10 \mathrm{mg} / \mathrm{kg} \mathrm{BW})$, on the other hand, marginally increased the concentrations of uric acid compared to controls, in both the DR and AL birds. The increase of $11 \%$ to $16 \%$ was associated with only slightly reduced shear values at wk 22 . Interestingly, the hemin associated increase in uric acid did not lower the oxidative stress but rather enhanced it. Hemin is a blood product and a source of iron. A growing body of evidence indicates that transition metals such as iron catalyze the formation of reactive oxygen species and stimulate lipid peroxidation (Tappel, 1985). This relationship between metal ions, oxygen radicals, and tissue damage has been 
reviewed (Aust, 1985; Ryan and Aust, 1992). In our studies, hemin induced considerable $(\mathrm{p}<0.001) \mathrm{CL}$ induced oxidative stress and increased Total Leukocyte Count (TLC) in the AL, 16 and 22 wk and DR, 16 wk birds. Our results are thus in agreement with previous studies that ascribe oxidative stress capacity to hemin.

Changes in uric acid concentrations were also associated $(\mathrm{p}<0.001)$ with changes in the accumulation of Ps concentrations, particularly with duration of treatment. Concentrations of Ps were lower in DR birds compared to AL. In agreement with previous studies in birds, concentrations of Ps, and possibly other AGEs, are not associated with elevated concentrations of plasma glucose even if conditions of high body temperature and metabolic rate are conducive to their formation (Iqbal et al., 1999). Our studies show no significant effects of either allopurinol or hemin on plasma glucose concentrations. Even in the DR group, there was no suggestion that feed restriction lowered glucose concentrations. This is in agreement with earlier findings in birds (Iqbal et al., 1999) but not with results in mammals where variable effects of DR have been reported. A 10\% decrease in blood glucose concentrations in DR rats (Sell et al., 1996) and an approximately $11 \%$ decrease in glucose in DR rodents ( Masoro et al., 1989) has been reported. This decrease in glucose is associated with a decrease in the glycation of proteins which might be caused by the decreased oxidative stress in DR animals (Sell et al., 1996; Masoro et al., 1989). While several studies have firmly established that collagen glycosylation is increased with age in many tissues, others have failed to demonstrate anything substantial but a cursory relationship between crosslinking and glycosylation, either in vivo or in vitro (Guitton et al.,1981; LePape et al., 1984; Lyons et al., 1991; Monnier et al., 1990). As an example, the amount of glycated $\mathrm{Hb}$ in hummingbirds, which has plasma glucose concentrations in excess of 
$650 \mathrm{mg} / \mathrm{dl}$, is about $2-5 \%$, much lower than measured in mammals which have levels ranging from 6-8\% (Beuchat and Chong, 1997).

The reduction in uric acid concentrations, at wk 22 in both the DR and AL birds, as a result of allopurinol feeding was associated with an increase in shear force value of the pectoralis major muscle. This observation supports our hypothesis that uric acid is an important antioxidant in birds. The reason for the increase in SF values has not been established although the increase in the concentration of the intramolecular crosslink Ps can be associated with an increased level of oxidative stress and glycation. A reduction in uric acid concentration is suggested to accelerate the formation of glycoxidation products. This view is supported by the observations of some other workers ( Yu et al., 1982; Youngman et al., 1992; Yu, 1993).

Allopurinol and oxypurinol were demonstrated to have free radical scavenging activity. However the concentration of allopurinol in such experiments exceeds physiologic serum concentrations by several orders of magnitude. The hydroxyl radical scavenging activity of allopurinol ( Morehouse, 1987) required concentrations in excess of $0.5 \mathrm{mM}$. Daily administration of allopurinol to cats $(50 \mathrm{mg} / \mathrm{kg} / \mathrm{day})$ produce serum concentrations of only 12.0 FM. Faure et al. (1990) have reported that allopurinol inhibits radiation-induced lipid peroxidation in rat erythrocytes and suggested that it had direct antioxidant activity. In his experiments, the allopurinol concentration was reported to be $20 \mathrm{mM}$, nearly 200 times the pharmacologically achieved, serum concentrations. In the current study antioxidant effects of allopurinol were unlikely due to the extremely low concentrations utilized. Allopurinol significantly $(\mathrm{p}<0.001)$ depressed body weight and breast weight, particularly at wk 22 , both DR and AL, and at wk 16, in the AL birds. There was also increased (40\%) mortality by wk 22. There are several reports in the literature documenting the toxicity of allopurinol in humans. In 
support of these findings, was our observation that allopurinol treated birds showed a reduction in feed consumption. This may have been due to development of hypertonicity. Similar results have been reported in turkey pullets (Robertson et al., 1986) and humans (Hande et al., 1984). The reason seems to be that plasma oxypurinol concentrations become several times greater than that required to prevent uric acid formation. Other investigators surmise that decreased uric acid excretion during long term therapy with allopurinol alters the tubular reabsorption of oxypurinol if uric acid and oxypurinol share the same transport mechanism (Berlinger et al., 1985). Since allopurinol is well absorbed orally and has a half life of $0.6-1.6 \mathrm{hr}$ it is rapidly converted to oxypurinol which is excreted in urine unchanged (Applebum et al., 1982). In humans, it has been reported a decrease in the intake of protein alters tubular transport of uric acid (Mehta, 1983). While it minimally affected renal clearances of allopurinol it has a marked effect on renal clearance of oxypurinol. Other reported side effects of allopurinol include gastrointestinal intolerance and vasculitis (Fox and Kelley, 1985; Mehta, 1983). Additional studies are required to determine whether any of these side effects may be responsible for the allopurinol toxicity observed in our studies and in the turkey pullets.

In conclusion, our investigation has documented that a reduction in uric acid concentration is associated with increase in oxidative stress, accumulation of the glycoxidation product Ps, and a decline in shear force values of the pectoralis major muscle. In view of our findings about the toxicity of allopurinol and oxypurinol both the dosage and duration (short vs. extended time scale) and route of administration require additional evaluation. Hemin, while effective at increasing uric acid concentrations, was demonstrated to be an inducer of oxidative stress. The response of the birds to the increase in uric acid was likely masked by hemin induced oxidative stress and discrimination between the two responses is complicated. 


\section{ACKNOWLEDGMENTS}

The authors wish to thank Vincent M. Monnier, Institute of Pathology, Case Western Reserve University for supplying the pentosidine standard and other technical guidance. We are also grateful to Nabil Al-Humadi, NIOSH for his valuable assistance in the HPLC analyses, Hakan Kocamis for technical assistance and Edwin C. Townsend for his help with the statistical analysis.

\section{REFERENCES}

Ames, B.N., R. Cathcart, E. Schwiers, and P. Hochstein, 1981. Uric acid provides an antioxidant defense in humans against oxidant- and radical-caused aging and cancer: A hypothesis. Proc. Natl. Acad. Sci. U.S.A. 78:6858-6862.

Appelbaum, S. J., M. Mayersohn, R. T. Dorr, and D. Perrier, 1982. Allopurinol kinetics and bioavailibility: intravenous, oral and rectal administration. Cancer Chemotherap. Pharmacol. 8: 93-98.

Aust, S.D., L.A.L Morehouse, and C.E. Thomas, 1985. Role of metals in oxygen radical reactions. J. Free Radic. Biol. Med. 1:3.

Bartges, J. W., C. A. Osborne, L. J. Felice, L. A. Koehler, L. K. Ulrich, K. A. Bird, and M. Chen, 1997. American Journal of Veterinary Research. 5:511-515.

Becker, F.B. 1993. Towards the physiological function of uric acid. Free Radic. Biol. Med. 14:615-631.

Berlinger, W. G., G. D. Park, and R. Spector, 1985. The effect of dietary protein on the clearance of allopurinol and oxypurinol. New Engl. J. Med. 313:771-776.

Beuchat, C.A., and C.R. Chong, 1997. Hyperglycemia in hummingbirds: Implications for 
hummingbird ecology and human health. FASEB J. 11:3:A91.

Bishop, M.L., J.L. Duben-Engelkink, and E.P. Fody, 1992. Clinical chemistry, principles, procedures, correlations. 2nd. Ed. Philadelphia, PA: Lippincott.

Cutler, R.G. 1984a. Antioxidants, aging, and longevity. In: Pryor, W.A., ed. Free Radicals in Biology. Vol. VI. Orlando: Academic Press. 371-428.

Cutler, R.G. 1984b. Urate and ascorbate: Their possible roles as antioxidants in determining longevity of mammalian species. Arch. Gerontol. Geriatr. 3:321-348.

Czarnecki, C. M., A. S. McVey, and D. K. Olivero, 1987. Evaluation of allopurinol as a cardioprotectant in ethanol-fed turkey pullets. 86C:67-71.

Faure, M., E. A. Lissi, and L. Videla, 1990. Antioxidant capacity of allopurinol in biological systems. Biochem. Int. 21:357-366.

Fox, I. H and W. N. Kelley, 1985. Uric acid and gout: In The Kidney: Physiology and Pathophysiology, Vol 2 (Edited by Seldin, D. W and G. Giebisch):1747-1764.

Guitton, J.D., A. Le pape, P.Y. Sizaret, and J.P. Muh, 1981. Influences of in vitro nonenzymatic glycosylation of type I collagen fibrillogenesis. Biosci. Rep. 1:945-954.

Hande, K. R., R. M. Noone, and W. J. Stone, 1984. Severe allopurinol toxicity. Am. J. Med. 74: 47-56.

Hellsten, Y., P.C. Tullson, E.A. Richter, and J.Bangsbo, 1997. Oxidation of urate in human skeletal muscle during exercise. Free Radic. Biol. and Med. 22:169-174. 
Holmes, J. D., and S. N. Austad, 1995. Birds as animal models for the comparative biology: prospectus. J. Geront: Biol. Sci. 50A:B59-B66.

Iqbal, M., L.L. Probert, and H. Klandorf, 1997. Effect of dietary aminoguanidine on tissue pentosidine and reproductive performance in broiler breeder hens. Poultry Sci. 76:1574-1579.

Iqbal, M., L.L. Probert, N.H. Al-humadi, and H. Klandorf, 1999. Protein glycosylation and advanced glycosylation endproducts (AGEs): An avian solution. J. Gerontol: Biol. Sci. 54:b171B176.

Iqbal, M., P.B. Kenney, H. Klandorf, 1999. Age-related changes in meat tenderness and tissue pentosidine: Effect of diet restriction and aminoguanidine in broiler breeder hens. Poultry Sci. In Press.

Kenney, P.B., S.D. Slider, R.R. Nayak, and J.W. Massey, 1996. Stunning method and time held in a transport coop affect $\mathrm{pH}$ decline and muscle quality in broilers. Poultry Sci. 75: (Suppl.1-72):55.

Klein, L., M.A. Butcher, O. Sudilovsky, R. Kikkawa, and M. Miller, 1975. Quantification of collagen from human nondiabetic and diabetic kidneys. Diabetes. 24:1057-1065.

Le Pape, A., J.D. Guitton, J.P. Muh, 1984. Distribution of non-enzymatically bound glucose in vivo and in vitro glycosylated Type I collagen molecules. FEBS Lett.170:23-27.

Lindstedt, S., and W. Calde, 1976. Body size and longevity in birds. Condor. 78:91-94.

Lyons, T.J., D.E. Bailie, D.G. Dyer, J.A. Dunn, and J.W. Baynes, 1991. Decrease in skin collagen glycation with improve glycemic control in patients with insulin-dependent diabetes mellitus. J Clin. Invest. 87:1910-1915. 
Masoro, E. J., M.S. Katz, C.A. Mcmahan, 1989. Evidence for the glycation hypothesis of aging from the food restricted rodent model. J. Gerontol. 44:B20-B22.

Maekawa, T., K. I. Ratinasamy, Y. K. Altman, and W. F. Forbes., 1970. Changes in collagen with age-I. The extraction of acid soluble collagens from skin of mice. Exp. Geront. 5:177-186.

Mehta, S. 1983. Drug disposition in children with protein energy malnutrition. J. Pediatr. Gastroenterol. Nutr. 2:407-417

Miller, D. M., T. A.Grover, N. Nayani, and S. D. Aust, 1993. Xanthine oxidase and iron dependent lipid peroxidation. Arch. Biochem. Biophys. 301:1-7

Monnier, V.M., V. Vishwanath, K.E. Frank, C.A. Elmets, P. Dauchot, and P.R. Kohn, 1986. Relationship between complications of type I diabetes mellitus and collagen-linked fluorescence. N. Engl. J. Med. 314:403-408.

Monnier, V. M. 1990. Nonenzymatic glycosylation, the Maillard reaction and the aging process. J. Gerontol: Biol. Sci. 45: B105-B111.

Morehouse, K. M., W. D. Flitter, and R. P. Mason, 1987. The enzymatic oxidation of desferal to a nitroxide free radical. FEBS Lett. 222:246-250.

Parmley, L., A.G. Mufti, and J.M. Downey, 1992. Allopurinol therapy of ischemic heart disease with infarct extension. Can. J. Cardiol. 8:280-286.

Radi, R., P. Cosgrove, J. S. Beckman, and B. A. Freeman, 1993. Biochem. J. 290: 51-57.

Robertson, J., D. Ratcliff, P. E. Bouton, P. V. Harris, and W. R. Shorthose, 1984. Effect of 
cooking temperature and animal age on the shear properties of beef and buffalo meat. J. Food Sci. 49:1163-1166.

Ross Breeders, 1996. Ross Breeder Management Guide. Ross Breeders, Huntsville, AL 35805

Ross, M. H. 1972. Length of life and caloric intake. Am. J. Clin. Nutr. 25:834-841.

Ryan, T. P. and S. D. Aust, 1992. The role of iron in oxygem mediated toxicities. Crit. Rev. Toxicol. 22:119-141.

SAS Institute, 1990. SAT/STAT7 Users Guide: Statistics. Release 6.04, SAS Institute Inc., Cary, $\mathrm{NC}$.

Schreiber, G., W., W. Tiemeyer, C.I. Flurer, and H. Zucker, 1986 Purine metabolites in serum of higher primates, including man. Int. J. Primatol. 7:521-531

Sell, D.R., A. Lapolla, P. Odetti, J, Fogarty, and V.M. Monnier, 1992. Pentosidine formation in skin correlates with severity of complications in individuals with long-standing IDDM. Diabetes. 41:1286-1291.

Sell, D.R., M.A. Lane, W.A Johnson, E.J., E.J. Masoro, O.B. Mock, K.M. Reiser, J.F., J.F. Fogarty, R.G. Cutler, D.K. Ingram, G.S. Roth, and V.M. Monnier, 1996. Longevity and the genetic determination of collagen glycoxidation kinetics in mammalian senescence. Proc. Natl. Acad. Sci. 93:485-490.

Shapiro, F., M. Mahagna, and I. Nir, 1997. Stunting syndrome in broilers: effect of glucose or maltose supplementation on digestive organs, intestinal disaccharidase, and some blood metabolites. Poult. Sci. 76:369-380. 
Shi, X., D. C. Flynn, D. W. Porter, S. S. Leonard, V. V. Vallyathan, and V. Castronova, 1997. Efficacy of taurine based compounds as hydroxyl radical scavengers in silica induced peroxidation. Ann of Clinical and Laboratory Science. 27:365-376.

Short, R., D.D.Williams, and D.M.Bowden, 1997. Circulating antioxidants as determinants of the rate of biological aging in Pigtailed Macaques (Macaca nemestrina). J Gerontol.: Biol. Sci. 52A:B26-B30.

Tappel, A. L.,1985. Unsaturated lipid oxidation catalyzed by hematin componds. J. Biol. Chem. 217:721-733.

Van Dyke, K., 1987. Cellular applications. In: Cellular Chemiluminescence, Vol 2 (Van Dyke, K and V. Castronova, eds), Boca Raton, FL, CRC Press: 41-182.

Youngman, L.D., J.Y. Park, and B.N. Ames, 1992. Protein oxidation associated with aging is reduced by dietary restriction of protein or calories. Proc. Natl., Acad. Sci. 89:9112-9116.

Yu, B.P., E.J. Masoro, I. Murafa, H.Q. Berfrand, and F.T. Lynd, 1982. Life-span study of SPF Fisher 344 male rats fed ad libitum or restricted diets: longevity, growth, lean body mass and disease. J. Gerontol.: Biol. Sci. 37:130.

Yu, B.P., 1993. Oxidative damage by free radicals and lipid peroxidation in aging. In: Yu, B.P., ed. Free radical in aging. Boca Raton, FL: CRC Press:57-88. 


\section{Table 1}

The amount of feed (g/day) provided on a daily basis for the diet restricted (DR) groups. The average daily food intake of the ad libitum (AL) fed birds is also presented.

$\underline{\text { Age, wk }}$

12

13

14

15

16

17

18

19

20

21

22 $\underline{\text { Ad libitum (AL) }}$

203

232

220

208

211

208

201

208

202

201

206 $\underline{\text { Diet restricted (DR) }}$

130

150

160

165

165

165

165

165

165

165

165 
Table 2. Mean and SEM of Uric Acid, Plasma Glucose, Total Leukocyte Count (TLC), Oxidative Stress and Skin Pentosidine

\begin{tabular}{|c|c|c|c|c|c|c|c|c|c|c|c|}
\hline \multicolumn{2}{|c|}{$\begin{array}{l}\text { Group } \\
\text { wk }\end{array}$} & \multicolumn{2}{|c|}{$\begin{array}{l}\text { Uric Acid } \\
\mathrm{mg} / \mathrm{dL} \\
\begin{array}{ll}16 & 22\end{array}\end{array}$} & $\begin{array}{l}\text { Glucose } \\
\text { mg/dL } \\
16\end{array}$ & 22 & $\begin{array}{l}\text { TLC } \\
\times 10^{5} \\
16\end{array}$ & 22 & \multicolumn{2}{|c|}{$\begin{array}{l}\text { Oxidative } \\
\text { stress, cpm } \\
\times 10^{5}\end{array}$} & \multicolumn{2}{|c|}{$\begin{array}{l}\text { Skin pentosidine } \\
\text { pmol/mg } \\
\text { collagen } \\
16\end{array}$} \\
\hline DR_C & $\begin{array}{l}\text { M } \\
\text { SEM }\end{array}$ & $\begin{array}{r}11.09 \\
0.79\end{array}$ & $\begin{array}{r}13.99 \\
3.19\end{array}$ & $\begin{array}{r}231.28 \\
3.80\end{array}$ & $\begin{array}{r}234.28 \\
4.75\end{array}$ & $\begin{array}{r}\mathbf{1 5 . 1 3} \\
0.01\end{array}$ & $\begin{array}{r}\mathbf{2 4 . 5 5} \\
7.43\end{array}$ & $\begin{array}{l}\mathbf{1 . 8 0} \\
0.47\end{array}$ & $\begin{array}{l}\mathbf{3 . 3 7} \\
1.28\end{array}$ & - & $\begin{array}{r}\mathbf{0 . 0 2} \\
.006\end{array}$ \\
\hline DR-A & $\begin{array}{l}\text { M } \\
\text { SEM }\end{array}$ & $\begin{array}{l}\mathbf{5 . 9 1} \\
0.84 \\
\end{array}$ & $\begin{array}{r}6.92 \\
1.00 \\
\end{array}$ & $\begin{array}{r}229.18 \\
6.86 \\
\end{array}$ & $\begin{array}{r}238.96 \\
8.03 \\
\end{array}$ & $\begin{array}{r}32.22 \\
2.38 \\
\end{array}$ & $\begin{array}{r}66.33 \\
14.21 \\
\end{array}$ & $\begin{array}{l}\mathbf{2 . 5 5} \\
0.57 \\
\end{array}$ & $\begin{array}{l}3.72 \\
0.87 \\
\end{array}$ & $\begin{array}{l}\mathbf{0 . 0 2} \\
0.004 \\
\end{array}$ & $\begin{array}{l}\mathbf{0 . 0 3} \\
0.003 \\
\end{array}$ \\
\hline DR_H & $\begin{array}{l}\mathbf{M} \\
\text { SEM }\end{array}$ & $\begin{array}{r}12.29 \\
1.06 \\
\end{array}$ & $\begin{array}{r}15.91 \\
2.03 \\
\end{array}$ & $\begin{array}{r}224.24 \\
3.45 \\
\end{array}$ & $\begin{array}{r}231.32 \\
7.28 \\
\end{array}$ & $\begin{array}{r}\mathbf{4 2 . 2 8} \\
2.32 \\
\end{array}$ & $\begin{array}{l}\mathbf{9 7 . 8 4} \\
34.99 \\
\end{array}$ & $\begin{array}{l}\mathbf{3 . 2 8} \\
1.01 \\
\end{array}$ & $\begin{array}{r}\mathbf{5 . 8 5} \\
1.72 \\
\end{array}$ & $\begin{array}{l}- \\
- \\
\end{array}$ & $\begin{array}{l}- \\
-\end{array}$ \\
\hline$A L \_C$ & $\begin{array}{l}\text { M } \\
\text { SEM }\end{array}$ & $\begin{array}{r}\mathbf{1 4 . 2 1} \\
0.62\end{array}$ & $\begin{array}{r}\mathbf{1 3 . 3 8} \\
2.87\end{array}$ & $\begin{array}{r}\mathbf{2 3 2 . 8 4} \\
3.42\end{array}$ & $\begin{array}{r}238.96 \\
8.03\end{array}$ & $\begin{array}{r}\mathbf{2 2 . 7 9} \\
2.03\end{array}$ & $\begin{array}{r}23.53 \\
5.02\end{array}$ & $\begin{array}{c}\mathbf{1 . 6 2} \\
0.56\end{array}$ & $\begin{array}{l}\mathbf{1 . 9 7} \\
0.44\end{array}$ & $\begin{array}{l}\mathbf{0 . 0 2} \\
0.008\end{array}$ & $\begin{array}{l}\mathbf{0 . 0 1} \\
0.006\end{array}$ \\
\hline AL_A & $\begin{array}{l}\text { M } \\
\text { SEM }\end{array}$ & $\begin{array}{r}\mathbf{1 0 . 6 0} \\
1.67\end{array}$ & $\begin{array}{r}13.21 \\
3.70\end{array}$ & $\begin{array}{r}224.08 \\
10.40\end{array}$ & $\begin{array}{c}\mathbf{2 2 5 . 5 8} \\
7.17\end{array}$ & $\begin{array}{r}37.08 \\
2.21\end{array}$ & $\begin{array}{l}\mathbf{7 3 . 6 0} \\
20.97\end{array}$ & $\begin{array}{l}\mathbf{1 . 7 9} \\
0.54\end{array}$ & $\begin{array}{l}\mathbf{3 . 7 3} \\
2.42\end{array}$ & $\begin{array}{l}\mathbf{0 . 0 2} \\
0.009\end{array}$ & $\begin{array}{c}\mathbf{0 . 0 8} \\
0.02\end{array}$ \\
\hline AL-H & $\begin{array}{l}\text { M } \\
\text { SEM }\end{array}$ & $\begin{array}{r}\mathbf{1 6 . 3 9} \\
1.08\end{array}$ & $\begin{array}{r}\mathbf{1 0 . 3 3} \\
0.37\end{array}$ & $\begin{array}{c}\mathbf{2 3 5 . 8 8} \\
3.75\end{array}$ & $\begin{array}{c}233.04 \\
4.79\end{array}$ & $\begin{array}{r}\mathbf{4 3 . 0} \\
1.74\end{array}$ & $\begin{array}{r}\mathbf{1 3 0 . 7 4} \\
29.05\end{array}$ & $\begin{array}{l}\mathbf{5 . 0 7} \\
1.06\end{array}$ & $\begin{array}{r}\mathbf{6 . 1 0} \\
1.42\end{array}$ & $\begin{array}{l}\mathbf{0 . 0 1} \\
0.007\end{array}$ & $\begin{array}{r}\mathbf{0 . 1 3} \\
0.05\end{array}$ \\
\hline
\end{tabular}

DR Diet Restriction AL ad libitum C Control A Allopurinol H Hemin M Mean SEM Standard error of mean 
Table 3. Mean and SE of Body Weight, Breast Weight and Breast Muscle Shear Value

\begin{tabular}{|c|c|c|c|c|c|c|c|}
\hline \multirow[t]{2}{*}{ Group } & \multirow[b]{2}{*}{ wk } & \multicolumn{2}{|c|}{ Body Wt, kg } & \multicolumn{2}{|c|}{ Breast Wt, gm } & \multicolumn{2}{|c|}{$\begin{array}{l}\text { Breast Muscle Shear } \\
\text { Force Value, pf/kg }\end{array}$} \\
\hline & & 16 & 22 & 16 & 22 & 16 & 22 \\
\hline DR_C & $\begin{array}{l}\text { M } \\
\text { SEM }\end{array}$ & $\begin{array}{l}\mathbf{1 . 5 6} \\
0.07\end{array}$ & $\begin{array}{l}2.10 \\
0.05\end{array}$ & $\begin{array}{r}\mathbf{9 2 9 . 3 0} \\
18.42 \\
\end{array}$ & $\begin{array}{c}\mathbf{1 0 5 2 . 4 4} \\
85.66\end{array}$ & $\begin{array}{l}\mathbf{1 . 8 8} \\
0.11\end{array}$ & $\begin{array}{c}\mathbf{2 . 1 4} \\
0.10\end{array}$ \\
\hline DR-A & $\begin{array}{l}\mathbf{M} \\
\text { SEM }\end{array}$ & $\begin{array}{l}\mathbf{1 . 4 7} \\
0.14 \\
\end{array}$ & $\begin{array}{c}1.35 \\
0.03 \\
\end{array}$ & $\begin{array}{l}\mathbf{7 9 7 . 0 2} \\
76.18 \\
\end{array}$ & $\begin{array}{r}\mathbf{5 3 6 . 5 4} \\
87.12 \\
\end{array}$ & $\begin{array}{l}\mathbf{2 . 0 9} \\
0.12 \\
\end{array}$ & $\begin{array}{c}4.04 \\
0.51 \\
\end{array}$ \\
\hline DR_H & $\begin{array}{l}\mathbf{M} \\
\text { SEM }\end{array}$ & $\begin{array}{l}\mathbf{1 . 7 6} \\
0.05\end{array}$ & $\begin{array}{l}2.18 \\
0.05\end{array}$ & $\begin{array}{r}885.09 \\
35.99\end{array}$ & $\begin{array}{r}\mathbf{9 8 7 . 6 6} \\
28.08\end{array}$ & $\begin{array}{l}\mathbf{2 . 0 9} \\
0.12\end{array}$ & $\begin{array}{c}\mathbf{1 . 9 8} \\
0.17\end{array}$ \\
\hline AL-C & $\begin{array}{l}\text { M } \\
\text { SEM }\end{array}$ & $\begin{array}{l}\mathbf{2 . 0} \\
0.03 \\
\end{array}$ & $\begin{array}{l}\mathbf{2 . 5 6} \\
0.08 \\
\end{array}$ & $\begin{array}{r}1042.44 \\
59.88 \\
\end{array}$ & $\begin{array}{r}\mathbf{1 2 4 6 . 4 8} \\
158.38 \\
\end{array}$ & $\begin{array}{l}\mathbf{1 . 9 4} \\
0.14\end{array}$ & $\begin{array}{c}2.24 \\
0.11 \\
\end{array}$ \\
\hline AL_A & $\begin{array}{l}\text { M } \\
\text { SEM }\end{array}$ & $\begin{array}{l}\mathbf{1 . 5 9} \\
0.10\end{array}$ & $\begin{array}{c}\mathbf{2 . 0 0} \\
0.13\end{array}$ & $\begin{array}{l}\mathbf{7 2 3 . 9 4} \\
37.44\end{array}$ & $\begin{array}{r}\mathbf{8 1 1 . 6 5} \\
49.98\end{array}$ & $\begin{array}{l}\mathbf{2 . 1 0} \\
0.12\end{array}$ & $\begin{array}{r}\mathbf{3 . 5 4} \\
0.51\end{array}$ \\
\hline AL-H & $\begin{array}{c}\mathbf{M} \\
\text { SEM }\end{array}$ & $\begin{array}{l}\mathbf{1 . 8 1} \\
0.05\end{array}$ & $\begin{array}{c}\mathbf{2 . 3 0} \\
0.08\end{array}$ & $\begin{array}{r}\mathbf{1 0 1 0 . 3 4} \\
52.43\end{array}$ & $\begin{array}{r}\mathbf{1 1 1 0 . 3 4} \\
151.37\end{array}$ & $\begin{array}{l}\mathbf{1 . 6 7} \\
0.11\end{array}$ & $\begin{array}{c}\mathbf{2 . 0 2} \\
0.12\end{array}$ \\
\hline
\end{tabular}

DR Diet Restriction AL ad libitum C Control A Allopurinol H Hemin M Mean SEM Standard error of mean 
Figure 3. Effect of allopurinol and hemin on plasma uric acid concentrations at 16 and 22 wk of age. Means with no common letters differ significantly $(P<0.05)$.

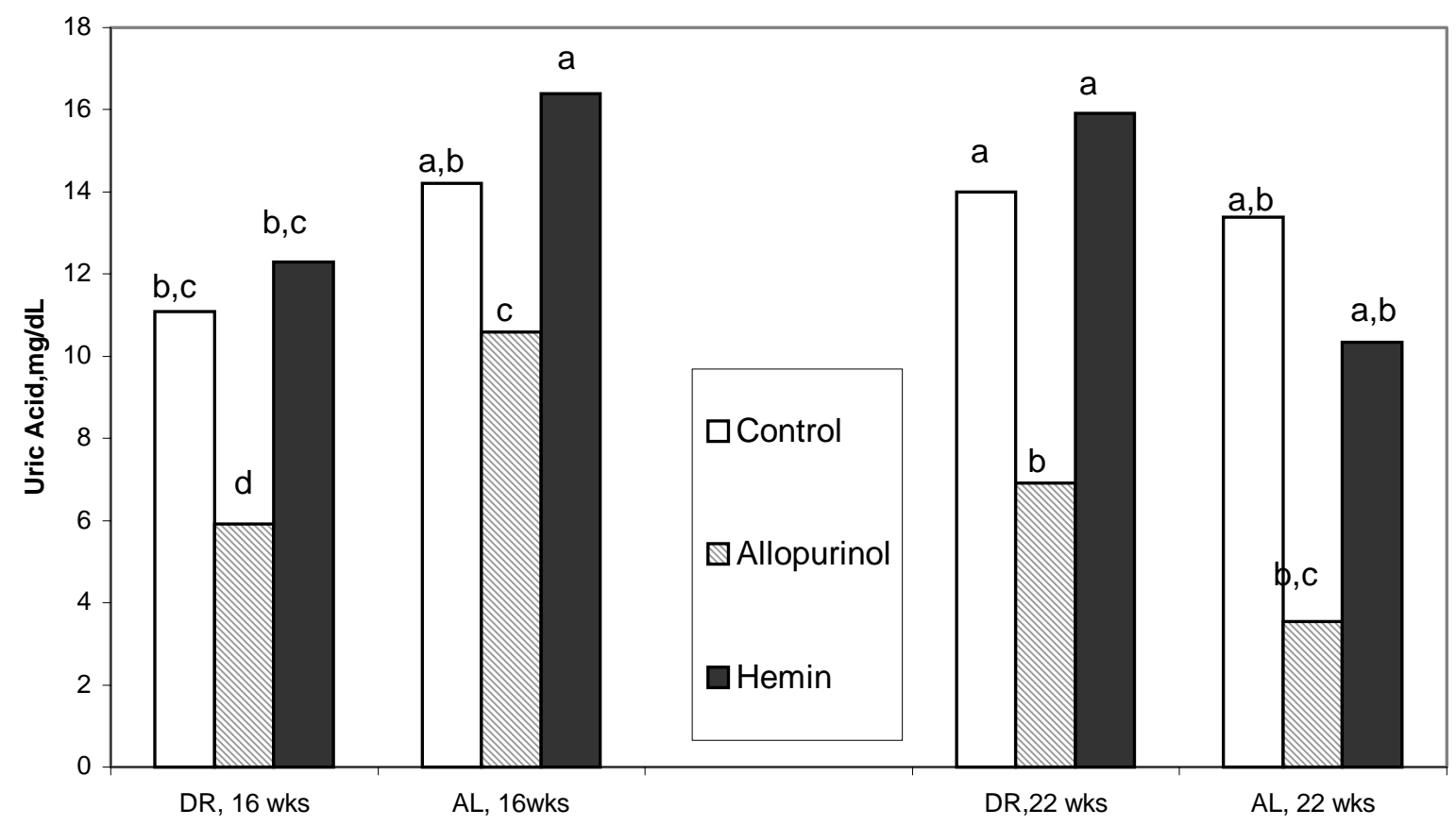


Figure 4. Effect of allopurinol and hemin on skin pentosidine, Ps, at 16 and 22 wk of age. Means with no common letters differ significantly $(P<0.05)$.

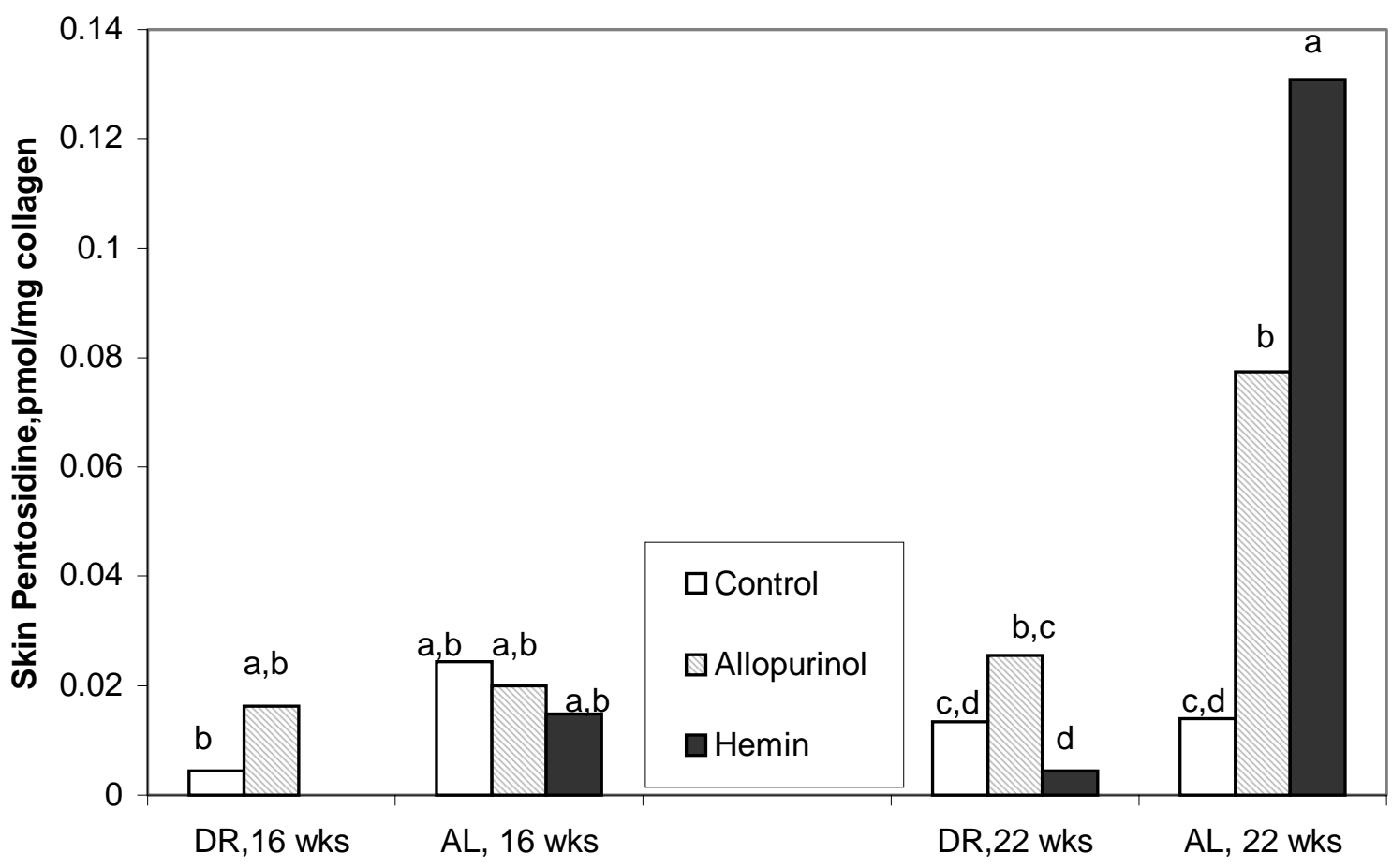


Figure 5. Effect of allopurinol and hemin luminol induced chemiluminescence detected oxidative stress at 16 and 22 wk of age. Means with no common letters differ significantly

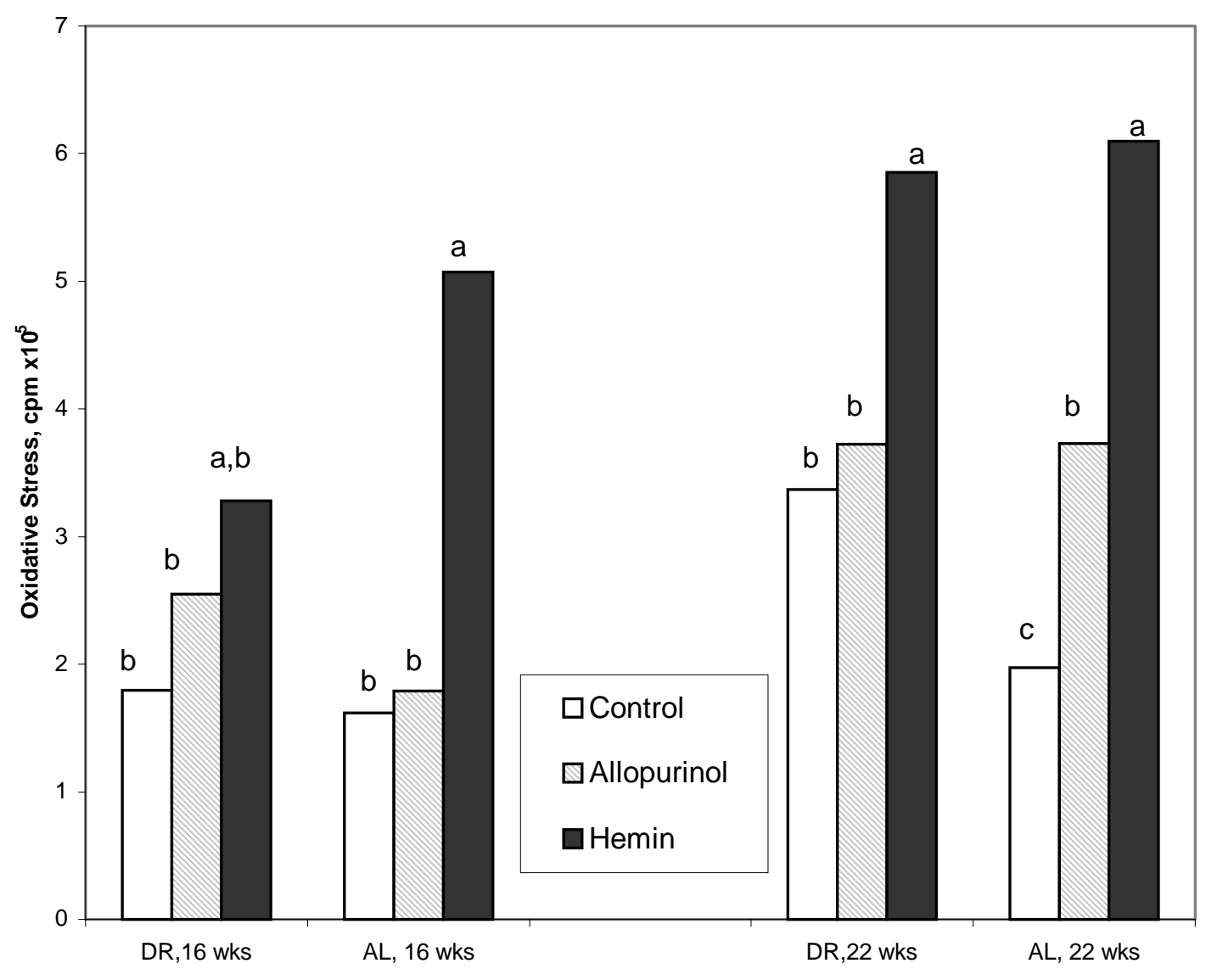

$(\mathbf{P}<\mathbf{0 . 0 5})$. 
Figure 6. Effect of allopurinol and hemin on breast weight at 16 and 22 wk of age.

Means with no common letters differ significantly $(P<0.05)$.

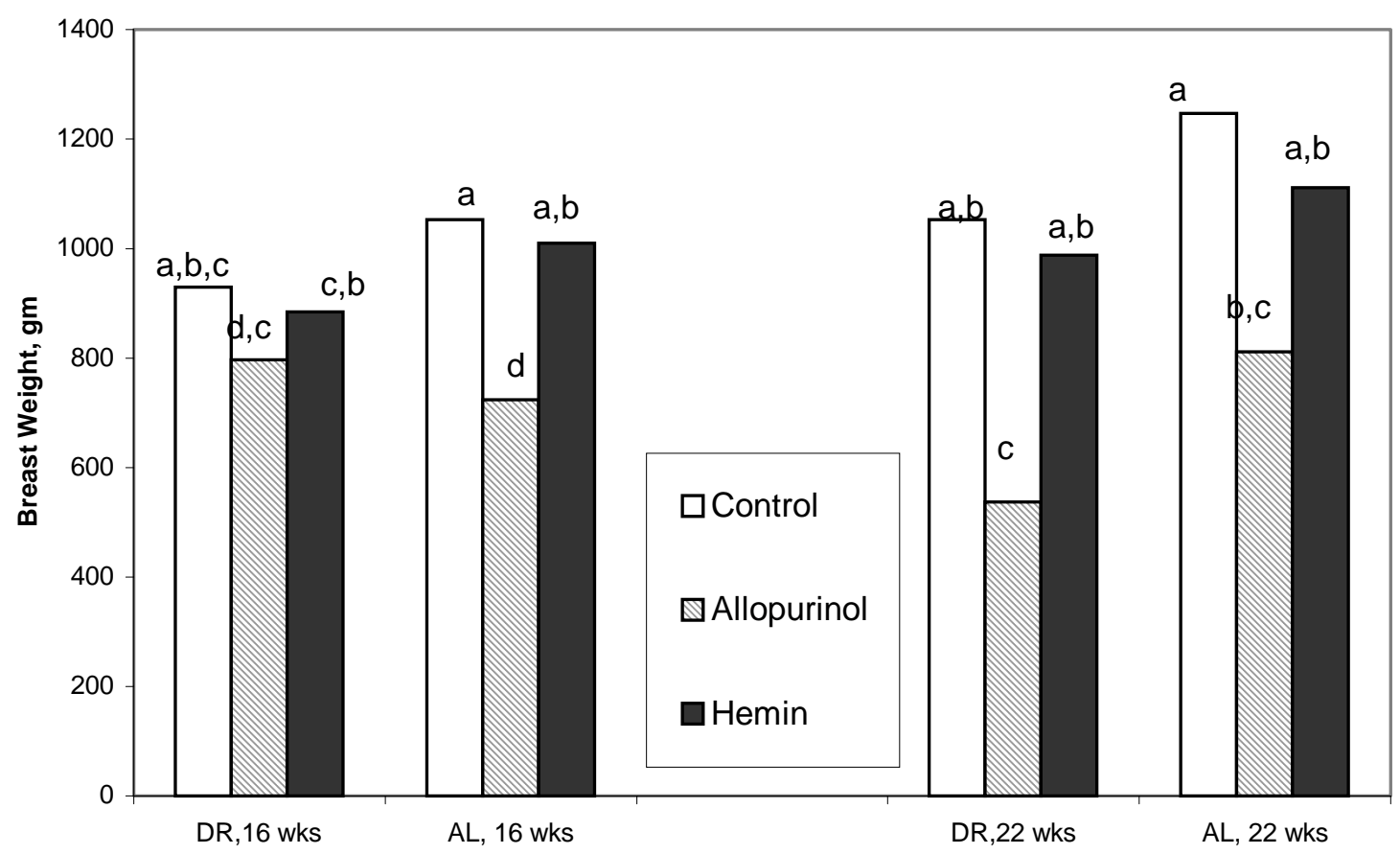


Figure 7. Effect of allopurinol and hemin on shear values (SV) at 16 and 22 wk of age. Means with no common letters differ significantly $(P<0.05)$.

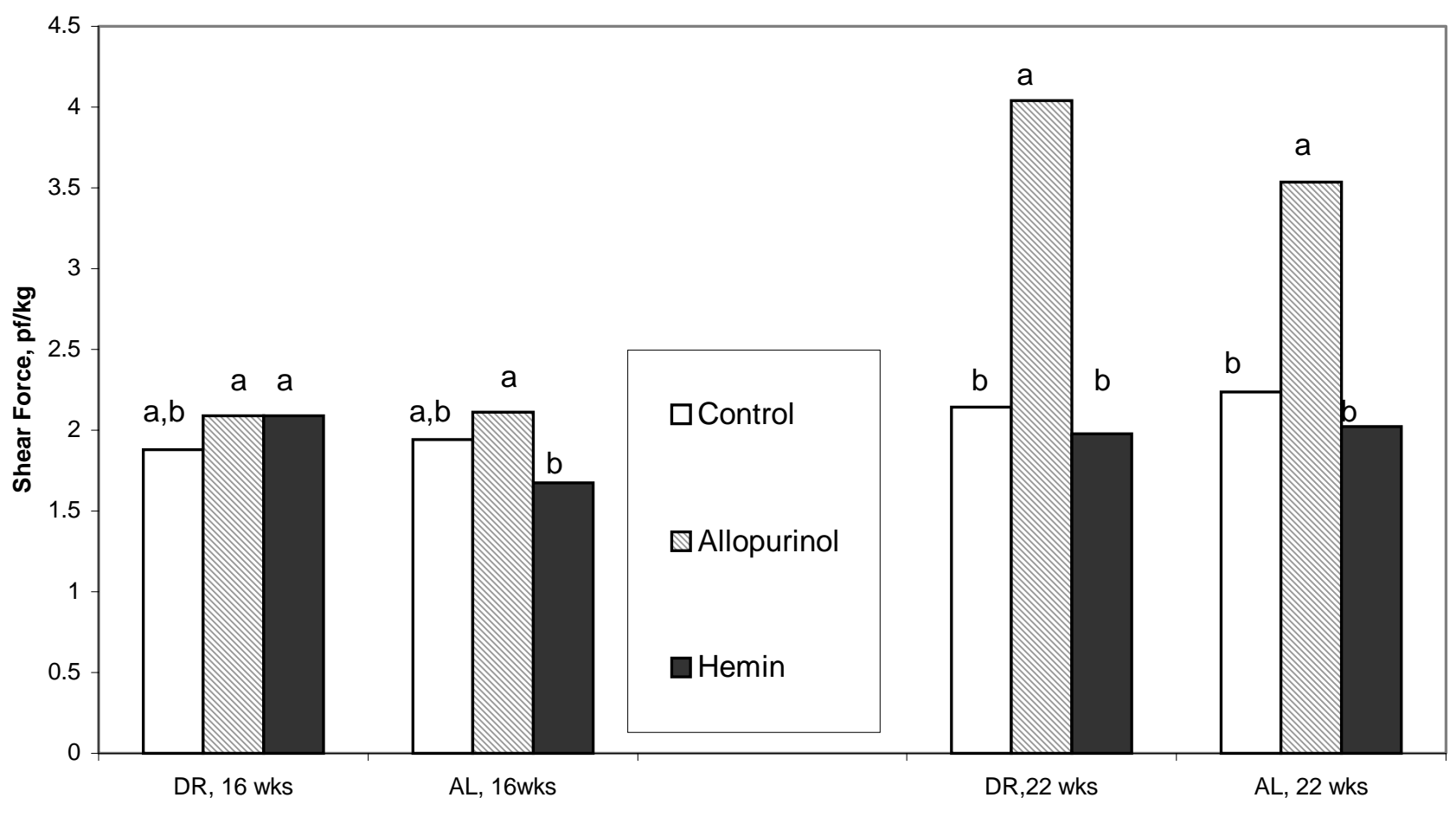


Figure 8. Effect of allopurinol and hemin on body weight at 16 and 22 wk of age.

Means with no common letters differ significantly $(P<0.05)$.

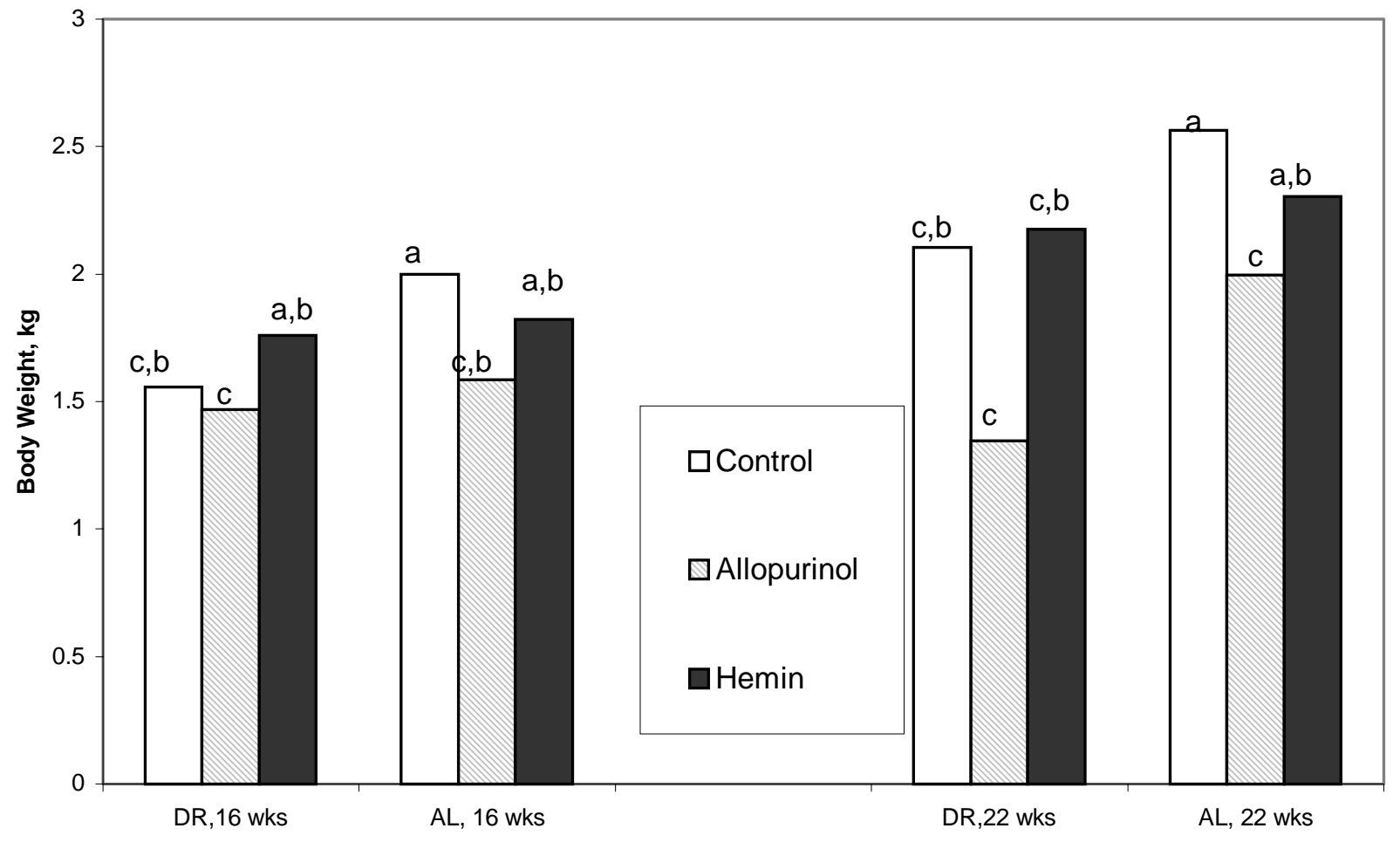




\title{
Study 2
}

\section{Effect of Uric Acid Manipulation on Ventricular Hypertrophy and Oxidative Stress in Broiler Chickens}

\begin{abstract}
Pulmonary hypertension syndrome (PHS) or Ascitis caused by valvular insufficiency and right ventricular failure has become a prominent cause of illness, death and condemnation in meat type chickens leading to substantial economic losses to the industry. Oxygen-derived free radicals play an important role in the genesis of tissue damage during inflammation and have been implicated in the pathogenesis of PHS. Antioxidants that can ameliorate this condition would be of potential use to poultry industry. The ability of uric acid to exert antioxidant ability has been known for several decades but it was first proposed to be an important biological antioxidant in 1981. The specific objectives of this study were to determine the effects of varying uric acid levels in broiler chickens on right ventricular hypertrophy and chemiluminescence dependent oxidative stress. The uric acid manipulation was done using allopurinol and hemin. Allopurinol $(\mathrm{P}<0.05)$ reduced plasma concentrations of uric acid, both in AL and DR birds. The reduction ranged from $26 \%$ to $74 \%$, being more pronounced by wk 22 . Hemin increased uric acid concentrations ranging from 11 to $16 \%$. Both allopurinol and hemin increased the RV:VT ratio, at wk 16 and 22. In the hemin group at wk 22, it was above the threshold ratio commonly assigned to ascitis (0.28). Hemin and allopurinol elevated the total leukocyte count, at 16 and 22 wk. Hemin increased the chemiluminescence dependent oxidative stress, $(\mathrm{P}<0.05)$ at 22 wk in both the DR and AL groups and in the AL birds at $16 \mathrm{wk}$. Hemin, while effective at increasing uric acid concentrations, was demonstrated to be an inducer of oxidative stress. This probably increased the
\end{abstract}


RV:VT ratio disposing birds to pulmonary hypertension syndrome (PHS). The response of the birds to the increase in uric acid was probably masked by hemin induced oxidative stress and discrimination between the two responses is complicated.

Key words: Pulmonary hypertension syndrome (PHS), Ascitis, Uric acid, Oxidative stress, 
The past 40 years have seen rapid growth and improved feed efficiency in meat type chickens. These factors have been implicated in musculoskeletal and cardiovascular diseases (Riddell, 1992; Julian, 1993, 1998). Ascitis, also called pulmonary hypertension syndrome (PHS), caused by valvular insufficiency and right ventricular failure has become a prominent cause of illness, death and condemnation in meat type chickens leading to substantial economic losses to the industry (Bottje et al., 1997; Julian, 1998). Oxygen-derived free radicals play an important role in the genesis of tissue damage during inflammation (Halliwell and Cutteridge, 1990) and it is thought that these may play an important role in the development of PHS (Enkvetchakul et al., 1993; Bottje et al., 1995). Oxidative stress is a general term used to describe a state of change caused by reactive oxygen species (ROS) (Van Dyke et al., 1987). This damage can affect a specific molecule or the entire organism. All the different sources of ROS can cause oxidative damage to an organism. Most of the ROS come from endogenous sources as by-products of normal and essential reactions, such as energy generation from mitochondria or the detoxification reactions involving the liver cytochome P-450 system. Exogenous sources include bacterial, fungal or viral diseases. Bottje et al., (1995) have reported results that indicate a protective role of - -tocopherol in lowering PHS mortality through improved tissue antioxidant capacity though the added costs of labor and implants would not make it practical. Uric acid has been hypothesized as one of the most important antioxidants. The ability of uric acid to exert antioxidant ability has been known for several decades but it was first proposed to be an important biological antioxidant in 1981 (Ames et al., 1981). Uric acid is produced by the oxidation of hypoxanthine and xanthine by xanthine oxidase and dehydrogenase 
enzymes. In most species, another enzyme, urate oxidase, converts it into allantoin, which is further converted to allantoate and then gloxylate plus urea. It has also been proposed as a potent scavenger of free radicals in human and many animal tissues (Hellsten et al., 1997). It has been established that urate, in vitro, has the ability to scavenge peroxides, hydroxyl radical species and hypochlorus acid. It is estimated to supply 30-65\% of the peroxyl radical scavenging ability (Becker, 1991). Humans, the most longer lived amongst primates, have comparatively high levels of uric acid because they lack uricase, the terminal degenerative enzyme present in monkeys and other mammals (Ames, et al., 1981). Uric acid is ubiquitous and it has been shown to decrease with increase in reperfusion injury in humans following myocardial infarction (Parmley et al., 1992).

In the current study, the specific objectives were to determine the effects of varying uric acid levels in broiler chickens on right ventricular hypertrophy and chemiluminescence dependent oxidative stress. The uric acid manipulation was done using allopurinol and hemin. Allopurinol is a structural analogue of the natural purine base, hypoxanthine and is a potent inhibitor of xanthine oxidase, the enzyme that converts hypoxanthine to xanthine and of xanthine to uric acid (Bartges et al., 1997). Hemin, on the other hand, increases the concentration of uric acid (Miller et al., 1993).

\section{Birds and Management}

\section{Materials and Methods}

Commercial Ross Breeders ${ }^{1}$ broiler chicks $(n=90), 12$ wk old, were used for trial and maintained under standard husbandry practices. These included recommended temperatures, bell drinkers and pan feeders. Specifications for space, temperature, light and husbandry were

\footnotetext{
${ }^{1}$ Ross Breeders, Huntsville, AL 35805
} 
adhered to as per the broiler production manual supplied by the company. The birds were divided into two groups, diet Restricted (DR) and ad libitum (AL) and with three treatments within each group (Control, Allopurinol Fed, and Hemin Fed). An earlier trial demonstrated that plasma uric acid decreased $(\mathrm{P}<0.05)$ when allopurinol was fed at the rate of $10 \mathrm{mg} / \mathrm{Kg} \mathrm{BW}$ compared to controls. In contrast, there was increase at d 10 in plasma uric acid when hemin, at the rate of $10 \mathrm{mg} / \mathrm{Kg} \mathrm{BW}$, was fed. The diet restricted birds were fed with a limited allowance diet (Table 1). Birds were killed at 4 and 10 wk after the onset of trial.

\section{Uric Acid Determination}

Plasma uric acid ( $\mathrm{n}=5$ per treatment group) was determined using Uric Acid Reagent ${ }^{2}$ as per the guidelines of the manufacturer.

\section{Measurement of Right Ventricular Hypertrophy}

After killing the bird by electrical stunning, heart was removed, weighed, and right ventricle $(\mathrm{RV})$ and left ventricle plus septum $(\mathrm{LV}+\mathrm{S})$ separated and weights obtained. The ratio of RV to total ventricle (RV:TV) was calculated as an index of right ventricular hypertrophy, which is associated with the severity of pulmonary arterial pressure elevation in the animal leading to ascitis (Burton et al., 1968; Bottje et al., 1997)

\section{Measurement of Luminol-Based Chemiluminescence (LBCL) Oxidative Stress}

Chemiluminescence is a functional assay to study the release of oxidants from cells or tissues (Van Dyke et al., 1987; Radi et al., 1993). Luminol-Based Chemiluminescence (LBCL) Oxidative Stress was measured as described by Iqbal et al. (1999). One milliliter of blood from 16 and 22 wk old birds ( $n=5)$ was suspended in mono-polyresolving medium (ICN 16-980-49) and leukocytes were isolated by centrifugation. The total number of leukocytes was counted 
using a routine hemocytometric technique. To a $3 \mathrm{ml}$ luminometer tube were than added $100 \mu \mathrm{l}$ of leukocytes, $100 \mu \mathrm{l}$ luminol solution, $200 \mu \mathrm{l}$ PBS, and $100 \mu \mathrm{l}$ phorbol myristate acetate (PMA). Luminol was incorporated into the reaction cuvettes as an amplifying agent of chemiluminescence to study the oxidative activity. Luminol is first oxidized to an intermediate that subsequently converts to an aminophthalate product with the release of photon ( 425 nm). Luminol reacts with superoxide, nitric oxide, and their reaction product, peroxynitrite. The luminometer tube was placed into a luminometer ${ }^{2}$ with the temperature control set at $37^{0} \mathrm{C}$. Oxidative activity was determined by measuring the luminescence generated over 20 minutes. Results were reported as counts per minute (CPM). A PC running KINB software, which comes with the luminometer (Berthold model LB 9505C, D 7547 Wildbad 1, P. O. B. 160 Germany), analyzed the data. Luminescence was corrected for each group based on the number of leukocytes present.

\section{Statistical Analysis}

Data were analyzed by the general linear models procedure (SAS Institute, 1990). The Student-Newman-Keuls Multiple Range test was used to estimate the significance of difference between means.

\section{Plasma Uric Acid}

\section{Results}

Allopurinol $(\mathrm{P}<0.05)$ reduced plasma concentrations of uric acid, both in AL and DR birds (Figure 1). The reduction ranged from $26 \%$ to $74 \%$, being more pronounced by wk 22 . Uric acid concentration was marginally higher in the AL birds compared to the DR controls at wk 16 although the increase was not significant. Hemin increased uric acid concentrations at wk 16, with an increase of 11 to $16 \%$. At wk 22, there was an increase (14\%) only in the DR group. 


\section{Right Ventricular Hypertrophy}

Both allopurinol and hemin increased the RV:VT ratio, at wk 16 and 22 (Figure 2). In the hemin group at wk 22, it was above the threshold ratio commonly assigned to ascitis (0.28). DR birds, in general, had lowered RV:VT ratio as compared to the AL birds. Allopurinol reduced $(\mathrm{P}<0.05)$ the heart weight with prolonged feeding while hemin fed birds showed no significant changes over control birds. Hearts weighed less in the DR birds compared to AL birds.

\section{Chemiluminescence Dependent Oxidative Stress}

Hemin increased the chemiluminescence dependent oxidative stress, $(\mathrm{P}<0.05)$ at $22 \mathrm{wk}$ in both the DR and AL groups and in the AL birds at 16 wk. Allopurinol elevated $(\mathrm{P}<0.05)$ the oxidative stress in the AL wk 22 group (Figure 3). Both hemin and allopurinol elevated the total leukocyte count, both at 16 and $22 \mathrm{wk}$. This was much more pronounced $(\mathrm{P}<0.05)$ in hemin fed birds. There was 2.7 and 4.0 fold increase in the Total Leukocyte Count at wk 16 and 22, respectively, in the hemin fed birds (Figure 4).

\section{Discussion}

Previous studies have established that birds have higher concentrations of antioxidants in their bodies and appear more efficient in dealing with the oxidative stress as compared to mammals (Youngman et al., 1992; Yu et al., 1982 and Yu, 1993). Iqbal et al., (1997, 1999) hypothesized that uric acid plays an important role in limiting oxidative stress and subsequent accumulation of advanced glycosylation endproducts (AGEs), such as Ps. The present study deals with the effects of uric acid manipulation on right ventricular hypertrophy and chemiluminescence dependent oxidative stress. The administration of allopurinol to broiler chickens was shown to decrease plasma uric acid concentrations. The reduction ranged from $26 \%$ to $74 \%$, being more pronounced with the duration of the treatment. The lowering of the uric acid is explained on the basis of primary action of allopurinol i.e. inhibition of xanthine oxidase, 
an enzyme that is involved in the conversion of hypoxanthine to xanthine and xanthine to uric acid. This indicates that broiler chickens are responsive to allopurinol treatment and that the major metabolite of allopurinol, oxypurinol, is probably responsible for the inhibition of xanthine oxidase. In human subjects, many conditions result in hyperuricemia (gout, alcoholism, cardiac myopathy, etc) and in the search for appropriate animal models, poultry can also be a valuable tool since the uric acid levels can be manipulated. A lowering in the uric acid concentration was accompanied by a decrease in the body weight, breast muscle weight and heart weight and an increase ventricular hypertrophy as indicated by the elevated RV:VT ratio. The increased total leukocyte count (TLC) and the chemiluminescence dependent oxidative stress indicated the birds becoming predisposed to oxidative stress on prolonged lowered uric acid The decrease in uric acid concentrations was accompanied by reduced body, breast and heart weight. The reduction in breast weight was marked at wk 22 particularly in DR birds (49\%) compared to AL birds (40\%) The heart weight too decreased but not to that extent observed in breast weight. The RV:VT ratio increased becoming significant $(\mathrm{P}<0.05)$ only by wk 22 . This observation supports our hypothesis that uric acid is an important antioxidant in birds. In the current study antioxidant effects of allopurinol were unlikely due to extremely low concentrations utilized. Allopurinol significantly ( $\mathrm{p}<0.001)$ depressed body weight and breast weight, particularly at wk 22, both DR and AL, and at wk 16, in the AL birds. There are several reports in the literature documenting the toxicity of allopurinol in humans and animals. In support of this view, was our observation that allopurinol treated birds showed a reduction in feed consumption. This may have been due to development of hypertonicity. Similar findings have been reported in turkey pullets (Robertson et al., 1986) and humans (Hande et al., 1984). The reason seems to be that plasma oxypurinol concentrations become several times greater than that required to prevent uric acid formation. Other investigators surmise 
that decreased uric acid excretion during long term therapy with allopurinol alters the tubular reabsorption of oxypurinol if uric acid and oxypurinol share the same transport mechanism (Berlinger et al., 1985). Since allopurinol is well absorbed orally and has a half life of 0.6-1.6 hr it is rapidly converted to oxypurinol, which is excreted in urine unchanged (Applebum et al., 1982). In humans, it has been reported a decrease in the intake of protein alters tubular transport of uric acid (Mehta, 1983). While it minimally affected renal clearances of allopurinol it has a marked effect on renal clearance of oxypurinol. Other reported side effects of allopurinol include gastrointestinal intolerance and vasculitis (Fox and Kelley, 1985; Mehta, 1983). Additional studies are required to determine whether any of these side effects may be responsible for the allopurinol toxicity and breast and body weight reduction observed in our studies and in the turkey pullets.

Hemin, $(10 \mathrm{mg} / \mathrm{kg} \mathrm{BW})$, on the other hand, marginally increased the concentrations of uric acid compared to controls, in both the DR and AL birds. The increase of $11 \%$ to $16 \%$ was associated with. Interestingly, the hemin associated increase in uric acid did not lower the oxidative stress or reduce the ventricular hypertrophy but rather enhanced it. Hemin is a blood product and a source of iron. A growing body of evidence indicates that transition metals such as iron catalyze the formation of reactive oxygen species and stimulate lipid peroxidation (Tappel, 1985). This relationship between metal ions, oxygen radicals, and tissue damage has been reviewed (Aust, 1985; Ryan and Aust, 1992). In our studies, hemin induced considerable $(\mathrm{p}<0.001)$ CL induced oxidative stress and increased Total Leukocyte Count (TLC) in the AL, 16 and $22 \mathrm{wk}$ and DR, $16 \mathrm{wk}$ birds. Our results are thus in agreement with previous studies that ascribe oxidative stress capacity to hemin.

In conclusion, our investigation has documented that a reduction in uric acid concentration is associated with increase in oxidative stress and total leukocyte count. Also, our findings about the 
toxicity of allopurinol and oxypurinol both the dosage and duration (short vs. extended time scale) and route of administration require additional evaluation. Hemin, while effective at increasing uric acid concentrations, was demonstrated to be an inducer of oxidative stress. This probably increased the RV:VT ratio disposing birds to pulmonary hypertension syndrome (PHS). The response of the birds to the increase in uric acid was likely masked by hemin induced oxidative stress and discrimination between the two responses is complicated. Further studies on protective role of uric acid and on compounds that can raise uric acid levels without being stressors by themselves should are required.

\section{REFERENCES}

Ames, B.N., R. Cathcart, E. Schwiers, and P. Hochstein, 1981. Uric acid provides an antioxidant defense in humans against oxidant- and radical-caused aging and cancer: A hypothesis. Proc.Natl. Acad. Sci. U.S.A. 78:6858-6862.

Bartges, J. W., C. A. Osborne, L. J. Felice, L. A. Koehler, L. K. Ulrich, K. A. Bird, and M. Chen, 1997. American Journal of Veterinary Research. 5:511-515.

Becker, F.B. 1993. Towards the physiological function of uric acid. Free Radic. Biol. Med. 14:615-631.

Bottje., W. J, and R. F. Wideman, Jr., 1995. Potential role of free radicals in the etiology of pulmonary hypertension syndrome. Poult. Avian Biol. Rev. 6:211-231. 
Bottje., W. J, G. F. Erf, T. K. Bersi, S. Wang, D. Barnes, and K. W. Beers, 1997. Effect of Dietary dl- • and - -Tocopherol and Pulmonary Hypertension Syndrome (Ascitis) in Broilers. Poultry Sci. 76:1506-1512.

Burton, R. R., A. Joyce, and K. U. Ingold, 1982. First proof that vitamin E is a major lipidsoluble chain-breaking antioxidant in human plasma. Lancet. 2:327.

Enkvetchakul, B., W. J. Bottje, N. Anthony, R. Moore, and W. Huff, 1993. Compromised antioxidant status associated with ascitis in broilers. Poultry Sci. 72:2272-2280.

Halliwell, B., and J.M.C. Gutteridge, 1990. Role of free radicals and catalytic metal ions in human disease: an overview. Methods Enzymol. 186:1-85.

Hellsten, Y., P.C. Tullson, E.A. Richter, and J.Bangsbo, 1997. Oxidation of urate in human skeletal muscle during exercise. Free Radic. Biol. and Med. 22:169-174.

Iqbal, M., L.L. Probert, and H. Klandorf, 1997. Effect of dietary aminoguanidine on tissue pentosidine and reproductive performance in broiler breeder hens. Poultry Sci. 76:1574-1579.

Iqbal, M., L.L. Probert, N.H. Al-humadi, and H. Klandorf, 1999. Protein glycosylation and advanced glycosylation endproducts (AGEs): An avian solution. J. Gerontol: Biol. Sci. 54:b171B176.

Julian., R. J., 1993. Ascitis in Poultry. Avian Pathol. 22:419-454. 
Julian., R. J., 1998. Ascitis and Skeletal Deformities in Broilers. Poultry Sci. 77:1773-1780.

Miller, D. M., T. A.Grover, N. Nayani, and S. D. Aust, 1993. Xanthine oxidase and iron dependent lipid peroxidation. Arch. Biochem. Biophys. 301:1-7.

Parmley, L., A.G. Mufti, and J.M. Downey, 1992. Allopurinol therapy of ischemic heart disease with infarct extension. Can. J. Cardiol. 8:280-286.

Radi, R., P. Cosgrove, J. S. Beckman, and B. A. Freeman, 1993. Biochem. J. 290: 51-57.

Riddell., C., 1992. Non-infectious skeletal disorders of poultry: an overview, Pages 119-145 in: Bone Biology and Skeletal Disorders in Poultry. C. C. Whitehead, ed. Carfax Publishing Co., Abingdon, UK.

Ross Breeders, 1996. Ross Breeder Management Guide. Ross Breeders, Huntsville, AL 35805

Ryan, T. P. and S. D. Aust, 1992. The role of iron in oxygem mediated toxicities. Crit. Rev. Toxicol. 22:119-141.

SAS Institute, 1990. SAT/STAT7 Users Guide: Statistics. Release 6.04, SAS Institute Inc., Cary, NC.

Tappel, A. L.,1985. Unsaturated lipid oxidation catalyzed by hematin componds. J. Biol. Chem. 217:721-733.

Van Dyke, K., 1987. Cellular applications. In: Cellular Chemiluminescence, Vol 2 (Van Dyke, K and V. Castronova, eds), Boca Raton, FL, CRC Press: 41-182.

Youngman, L.D., J.Y. Park, and B.N. Ames, 1992. Protein oxidation associated with aging is 
reduced by dietary restriction of protein or calories. Proc. Natl., Acad. Sci. 89:9112-9116.

Yu, B.P., E.J. Masoro, I. Murafa, H.Q. Berfrand, and F.T. Lynd, 1982. Life-span study of SPF Fisher 344 male rats fed ad libitum or restricted diets: longevity, growth, lean body mass and disease. J. Gerontol.: Biol. Sci. 37:130.

Yu, B.P., 1993. Oxidative damage by free radicals and lipid peroxidation in aging. In: Yu, B.P., ed. Free radical in aging. Boca Raton, FL: CRC Press:57-88. 


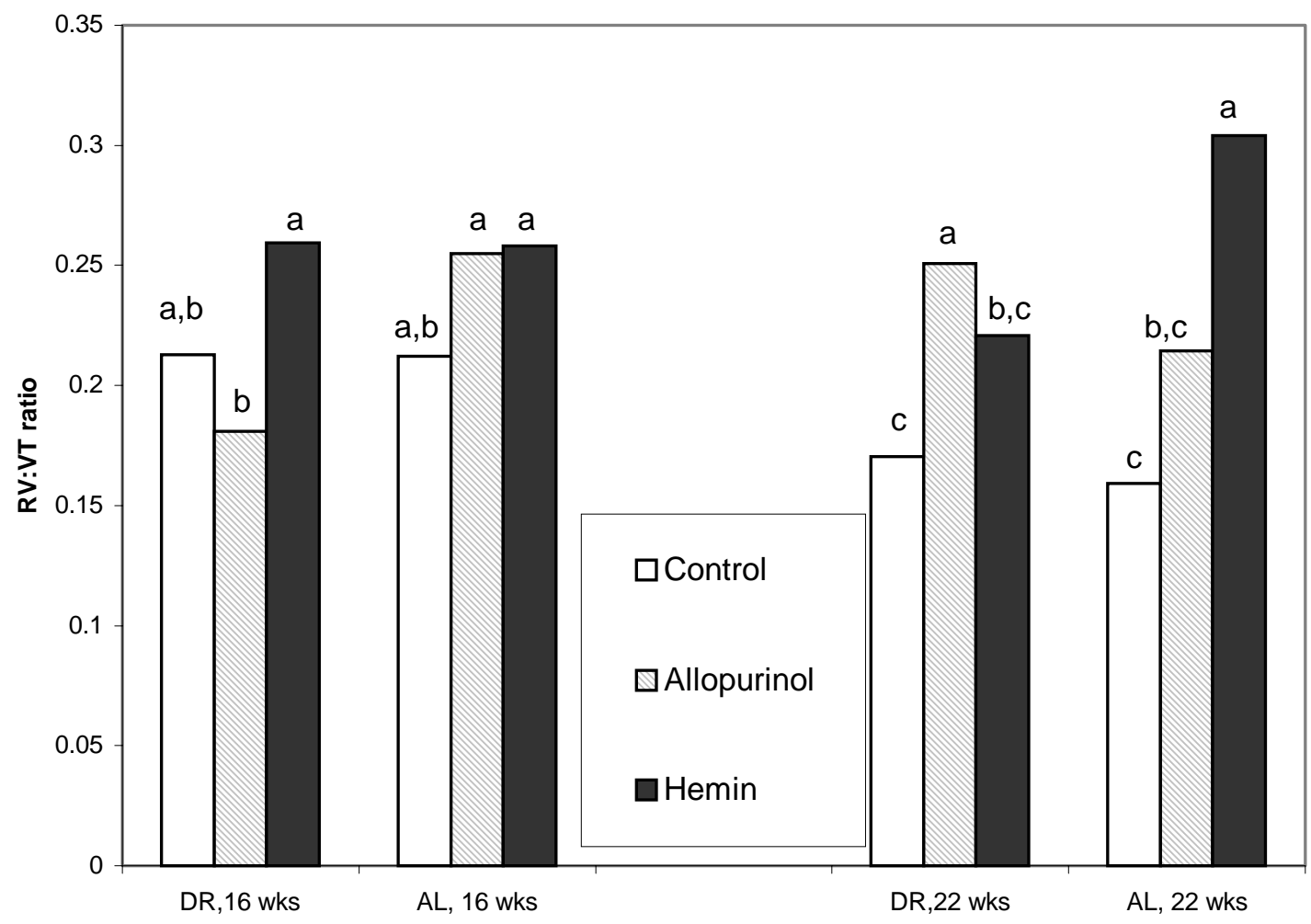

Figure 1. Effect of allopurinol and hemin on ventricular hypertrophy, as indicated by RV:VT ratio, at 16 and 22 wk in the DR and $A L$ group. Means with no common letters differ significantly. Comparisons should be made for the same age group. 


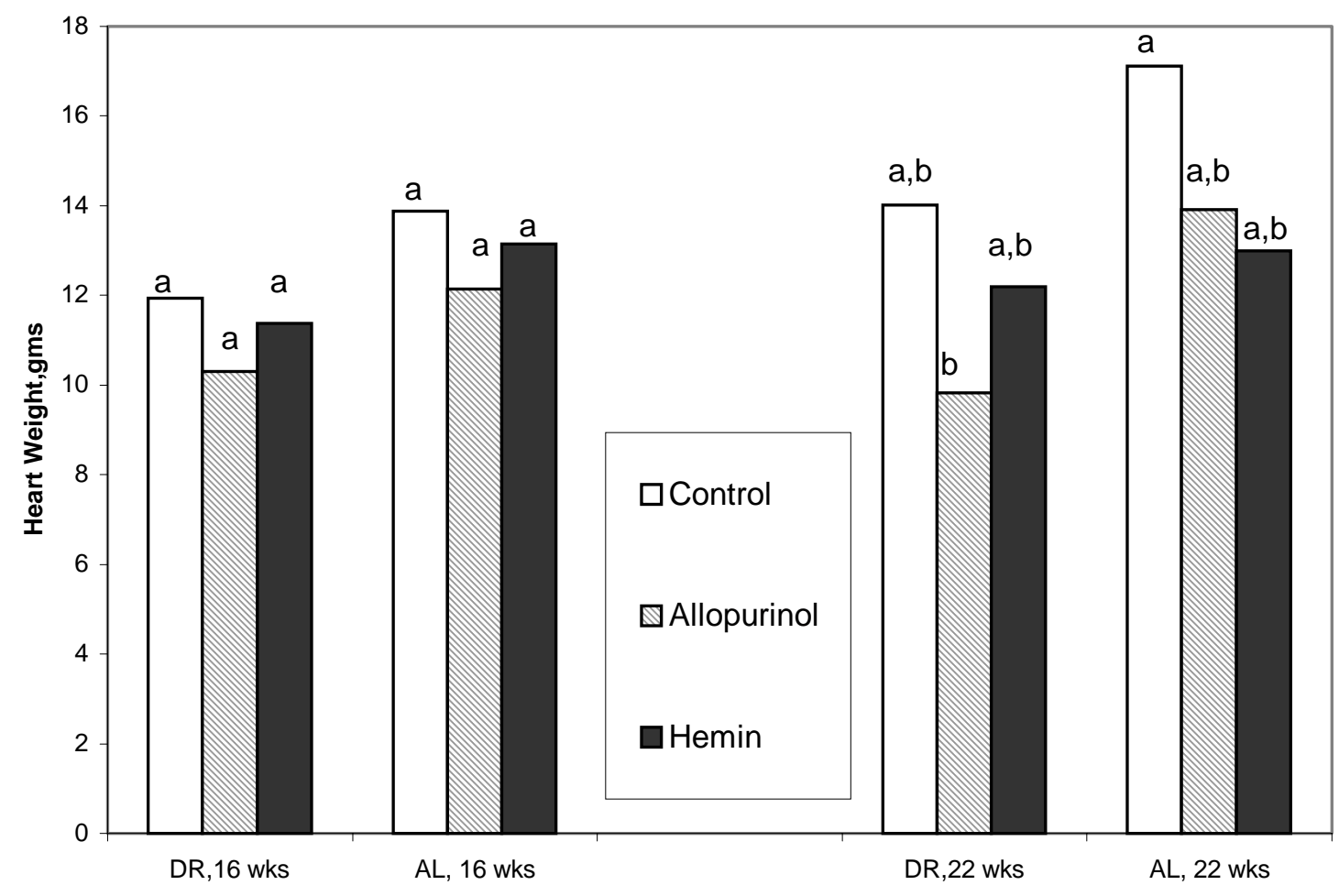

Figure 2. Effect of allopurinol and hemin on Heart Weight at 16 and 22 wk in the DR and AL group. Means with no common letters differ significantly. Comparisons should be made for the same age group. 


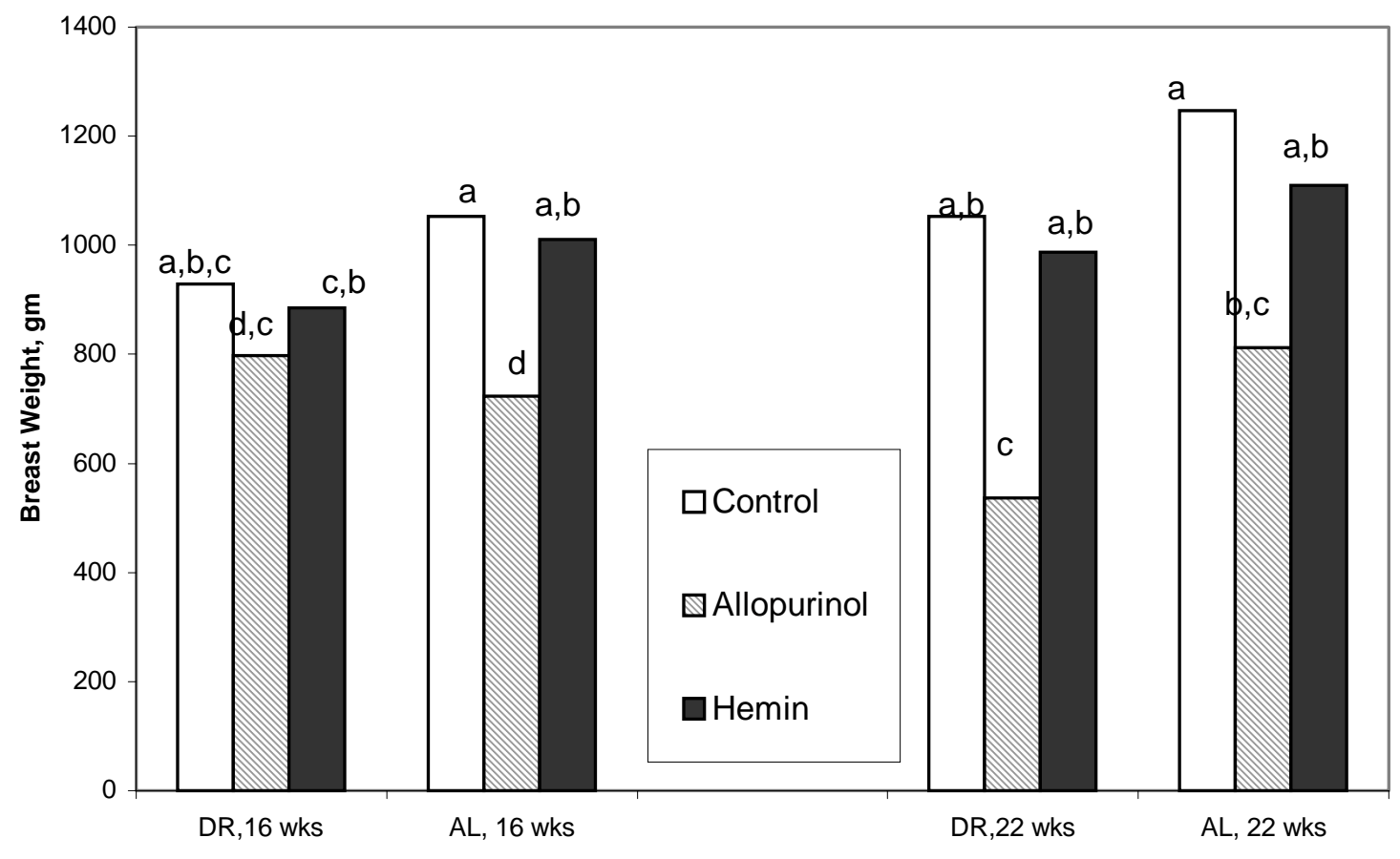

Figure 3. Effect of allopurinol and hemin on Breast Weight at 16 and 22 wk in the DR and AL group. Means with no common letters differ significantly. Comparisons should be made for the same age group. 


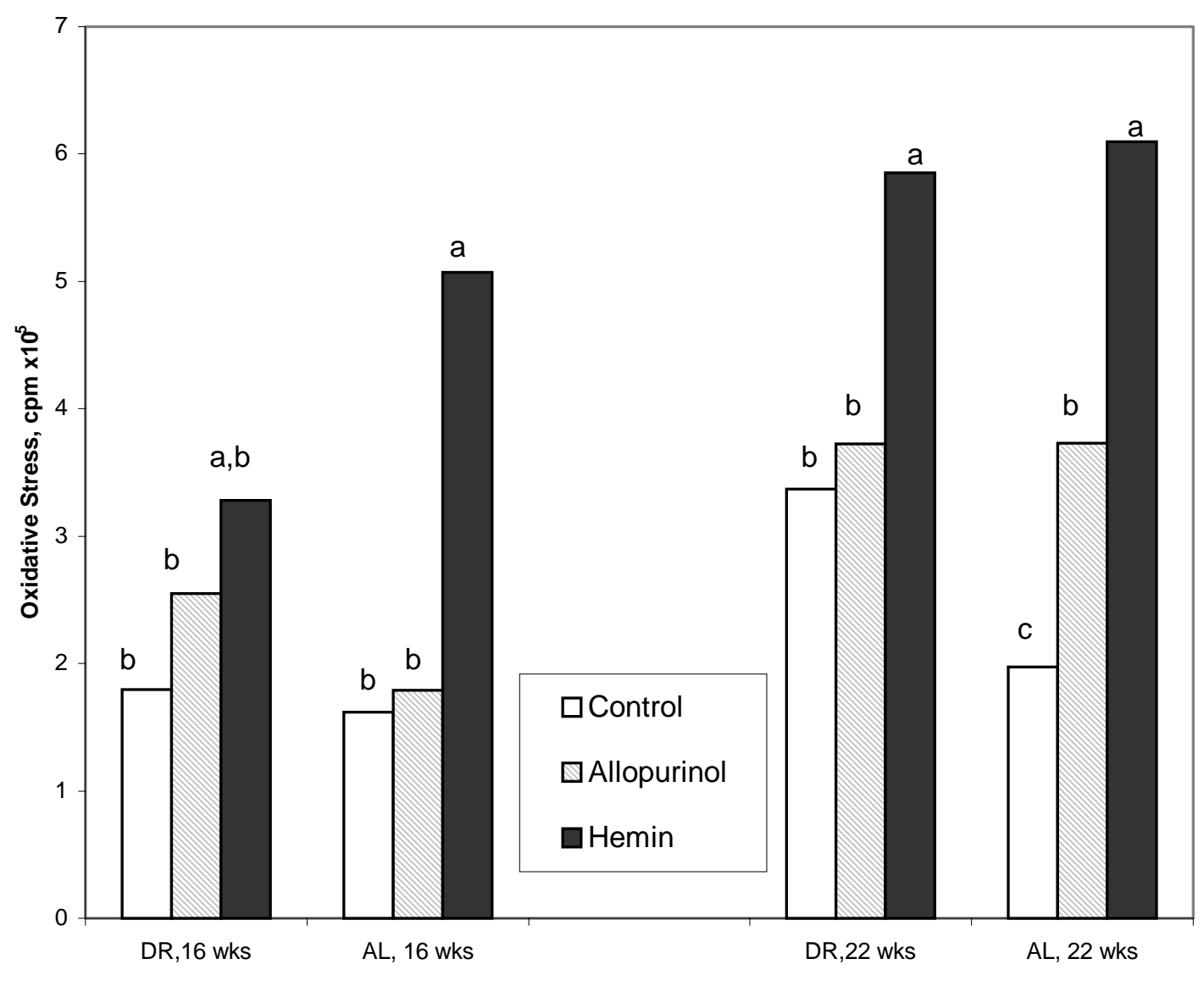

Figure 4. Effect of allopurinol and hemin on chemiluminescence dependent oxidative stress at 16 and $22 \mathrm{wk}$ in the DR and AL group. LBCL, luminol based chemiluminescence is a functional assay to study release of oxidants from cells, leukocytes in this case. Means with no common letters differ significantly. Comparisons should be made for the same age group. 


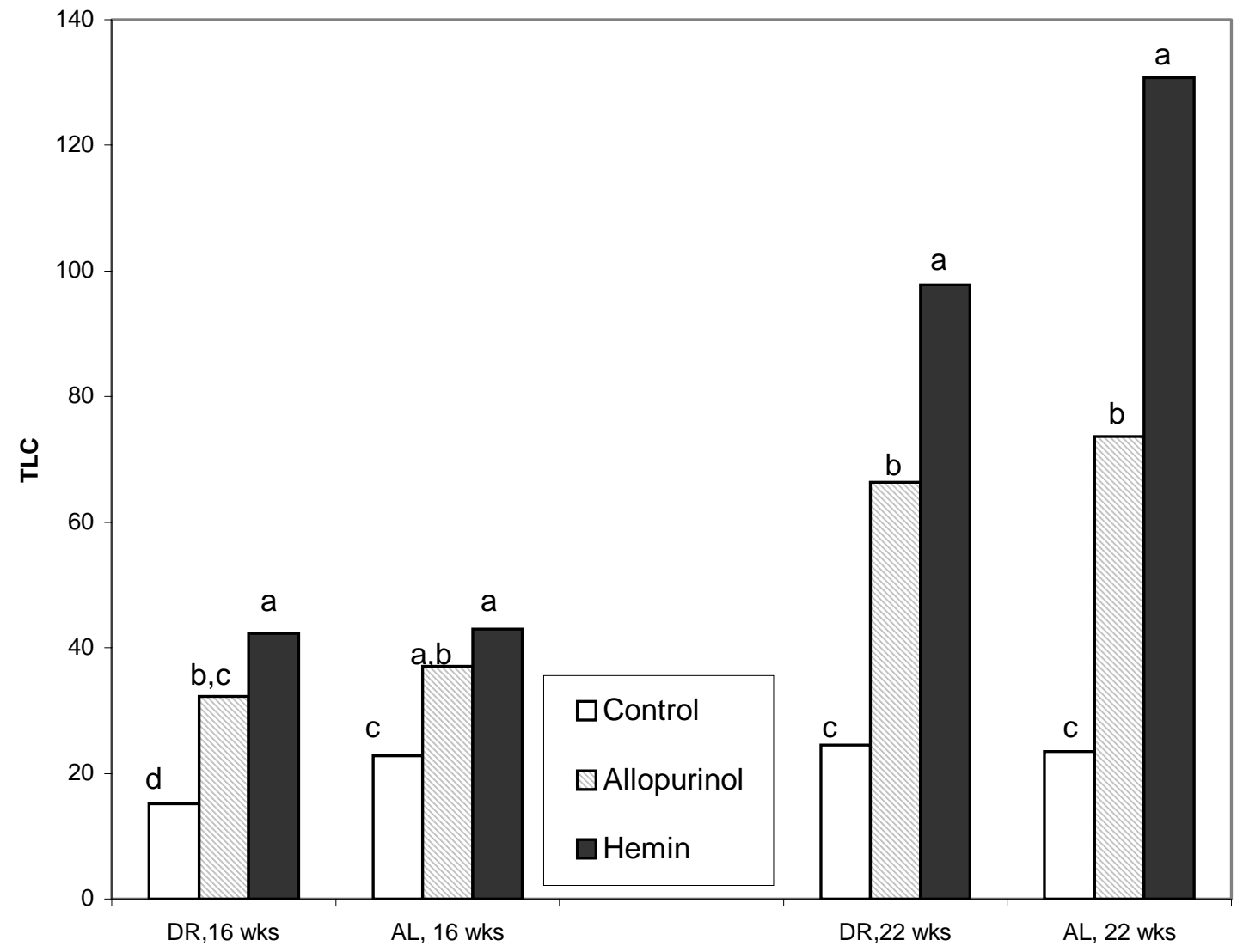

Figure 5. Effect of allopurinol and hemin Total Leukocyte Count (TLC) at 16 and 22 wk in the DR and AL group. Means with no common letters differ significantly. Comparisons should be made for the same age group. 


\section{Chapter 4}

\section{SUMMARY}

The study of life span, both in mammals and aves, and as to why one ages has been one of the most intriguing questions of our time. Aging has been studied in many animal models, but the avian species have not been well studied. People often question the choice of birds as animal model of aging. Why use birds? Birds offer manifold advantages as animal models for biogerontology. The maximum longevity in birds has been known to range from 4 years in blue jay ( Cyanocitta cristata) to 64 years in Macaw ( Ara macao). Their chief features relative to aging research are many and have been reviewed (Holmes and Austad, 1994). These traits include: (1) metabolic rates as much as 2 to 2.5 times as those of mammals of similar body sizes. (2) blood sugar levels typically 2 to 4 times as high as those of mammal's (3) do an elevated body temperature, about $3^{\circ} \mathrm{C}$ higher than mammals. These factors expose them to a higher rate of free oxygen radical production and accelerate formation of advanced Maillard products. Without special protective mechanisms against the potential for damage, birds should be comparatively short lived and age more rapidly than mammals. Therefore, an inquiry into the physiological mechanisms allowing birds to achieve their extended life spans will facilitate an understanding of basic aging process against them. It appears that birds have evolved mechanisms to limit the damage caused by these degenerative changes. Uric acid has been proposed as a potent scavenger of free radicals in human and many animal tissues (Hellsten et al., 1997). Thus, there is a critical need to evaluate the role of uric acid as an antioxidant. It is in this context that the present study was thought of and initiated. The main objective was to determine if Allopurinol and Hemin, could be used in effecting changes in uric acid levels in broiler chickens. Allopurinol is a structural analogue of the natural purine base, hypoxanthine 
and is a potent inhibitor of xanthine oxidase, the enzyme that converts hypoxanthine to xanthine and of xanthine to uric acid (Bartges et. Al., 1997). Hemins on the other hand potentates the level of uric acid (Miller et. Al., 1995). We proposed to determine if the changed uric acid levels, were influenced by diet regime (feed restricted vs. ad libitum feeding) and if any relationship could be established between the allopurinol/hemin intake level and aging markers, particularly skin pentosidine, and see how changed uric acid levels influenced breast weight and sheer force in broiler chickens. . In a pilot trial, the decrease in plasma uric acid, at day ten, was significant $(\mathrm{P}<0.05)$ when allopurinol was fed at the rate of $10-\mathrm{mg} / \mathrm{Kg}$-body weight. The reduction ranged from $26 \%$ to $74 \%$, being more pronounced by week 22 . The skin pentosidine level increased significantly $(\mathrm{P}<0.05)$ in the allopurinol fed birds, both DR and AL, at 22 weeks of age. There was no consistent response in hemin fed birds. Hemin increased the Chemiluminescence Dependent Oxidative Stress, significantly $(\mathrm{P}<0.05)$ at $22 \mathrm{wk}$, as also in the ad lib $16 \mathrm{wk}$. allopurinol elevated the oxidative stress, significantly, only in the ad-lib wk 22 group. Both hemin and allopurinol elevated the total leukocyte count, both at 16 and 22 weeks. This was much more pronounced and significant $(\mathrm{P}<0.05)$ in hemin fed birds. Allopurinol reduced both the body and breast weight, in both groups at both 16 and 22 wk. Decreased uric acid levels, at wk 22 in both the DR and AL birds, as a result of allopurinol feeding resulted in increased shear force values, which were statistically significant $(\mathrm{p}<0.001)$. This seems to be significant as it possibly puts a role to the antioxidant role of uric acid. an increased level of oxidative stress and glycation with the lowered uric acid might have advanced the formation of glycoxidation products by reducing the concentration of antioxidant enzymes, thus advancing the decline in meat tenderness 


\section{Chapter 5}

\section{BIBLIOGRAPHY}

Ames, B.N., Cathcart, R., Schwiers, E., Hochstein, P. 1981. Uric acid provides an antioxidant defense in humans against oxidant- and radical-caused aging and cancer: A hypothesis. Proc. Natl. Acad. Sci. U.S.A. 78:6858-6862.

Aust, S.D., Morehouse, L.A.L, and Thomas, C.E. 1985. Role of metals in oxygen radical reactions. J. Free Radic. Biol. Med. 1:3.

Austad, S., and Fischer, K. 1991. Mammalian aging, metabolism, and ecology: evidence from bats and marsupials. J. Gerontol: Biol. Sci. 46:B47-B53.

Bandy, B. and Davison, A. 1990. Mitochondrial mutations may increase oxidative stress: implications for carcinogenesis and aging? Free Radic. Biol. Med. 8:523.

Barja, G., Cadenas, S., Rojas, C., Perez-Compo, R., and Lopez-Torrez, M. 1994. Low mitochondrial free radical production per unit of consumptions can explain the simultaneous presence of high longevity and high aerobic metabolic rate in birds. Free Radic. Res. 21:37-328.

Baynes, J.W., Monnier, V.M. 1989. eds. The Maillard reaction in aging, diabetes and nutrition. In: Progress in clinical biology research. New York Alan R. Liss.

Baynes, J.W. 1991. Role of oxidative stress on development to complications in diabetes. Diabetes 40: 405-412.

Becker, F.B. 1993. Towards the physiological function of uric acid. Free Radic. Biol. Med. 14:615-631.

Berg, B.N., and H.S. Simms, 1960. Nutrition and longevity in the rat. II. Longevity and onset of disease with different levels of food intake. J. Nutr. 71:255-259.

Boje, K.M., and Arora, P.K. 1992. Microglial-produced nitric oxide and reactive nitrogen oxides mediate neuronal cell death. Brain Res. 587:250-256.

Cerami, A. 1985. Hypothesis: Glucose as a mediator of aging. J. Am. Geriatr. Soc. 33:626-634.

Cerami, A., Vlassara, J., and Brownlee, M., 1987. Glucose and aging. Science 256: 90-96.

Chou, M.W., Pegram, R.A., Gao, P., and Allaben, W.T., 1991. Effect of caloric restriction on aflatoxin Bl metabolism and DNA modification in Fischer-344 rats. In: Fishbein, L., ed. Biological effects of dietary restriction. Berlin: Springer Verlag ;42-54.

Comfort, A., 1979. The biology of senescence, 3rd ed. New York: Elsevier. 
Conlon, P., Smith, D., and Gowlett, T. 1991. Oxygen radical production by avian leukocytes. Can. J. Vet. Res. 55:193-195.

Cutler, R.G. 1984a. Antioxidants, aging, and longevity. In: Pryor, W.A., ed. Free Radicals in Biology. Vol. VI. Orlando: Academic Press. 371-428.

Cutler, R.G. 1984b. Urate and ascorbate: Their possible roles as antioxidants in determining longevity of mammalian species. Arch. Gerontol. Geriatr. 3:321-348.

Del Maestro, R. F. 1980. An approach to free radical in medicine and biology. Acta Physiol. Scand. 492:153-168.

Dyer, D.G., Blackledge, J.A., Thorpe, S.R., and Baynes, J.W. 1991a. Formation of pentosidine during nonenzymatic browning of proteins by glucose. J. Biol. Chem. 266:11554-11560.

Dyer, D.G., Blackledge, J.A., Thorpe, S.R., Baynes, J.W. 1991b. Formation of pentosidine during nonenzymatic browning of proteins by glucose: identification of glucose and other carbohydrates as possible precursors of pentosidine in vivo. J. Biol. Chem. 266:11654-11660.

Dyer, D.G., Dunn, J.A., Thorpe, S.R., and Lyons, T.J. 1992. Accumulation of Maillard reaction products in skin collagen in diabetes and aging. Annals of the NY Acad. of Sci. 663:421-422.

Esterbauer, J., and Schaur, R.J. 1990. Aldehyde formed by lipid peroxidation: Mechanisms of formation, occurrence, and determination. In: Bigo-Pelfrey, C., Ed. Membrane lipid oxidation. Boca Raton, FL: CRC Press :239-268.

Everitt, A.V., Wyndham, J.R., Barnare, D.L. 1983. The anti-aging action of hypophysectomy in hypothalamic obese rats: effects on collagen aging, age-associated proteinuria development and renal histopathology. Mech. Aging Dev.; 22:233-25.

Guitton, J.D., Le pape, A., Sizaret, P.Y., and Muh, J.P. 1981. Influences of in vitro nonenzymatic glycosylation of type I collagen fibrillogenesis. Biosci. Rep. 1;945-954.

Harrison, D.E., Archer, J.R., Sacher, G.A., and Boyce, F.M. 1992. Tail collagen aging in mice of thirteen different genotypes and two species: Relationship to biological age. Exp. Gerontol. 1978; 13:63-73.

Harman, D. 1956. Aging: A theory based on free radical and radiation chemistry. J. Gerontol. 11:298-300.

Hellsten, Y., Tullson, P.C., Richter, E.A., and Bangsbo, J. 1997. Oxidation of urate in human skeletal muscle during exercise. Free Radic. Biol. and Med. 22:169-174.

Holliday, R. 1992. The ancient origins and causes of ageing. News Physiol. Sci. 7:34-40. Holmes, J. D., and S. N. Austad, 1995. Birds as animal models for the comparative Biology: prospectus. J. Geront: Biol. Sci. 50A:B59-B66. 
Iqbal, M., Probert, L.L., and Klandorf, H. 1997. Effect of dietary aminoguanidine on tissue pentosidine and reproductive performance in broiler breeder hens. Poultry Sci. 76:1574-1579.

Iqbal, M., Probert, L.L., Al-humadi, N.H. and Klandorf, H. 1998 a. Protein glycosylation and advanced glycosylation endproducts (AGEs): An avian solution. J. Gerontol: Biol. Sci. In review.

Iqbal, M., Kenney, P.B., Klandorf, H. 1998 b. Age-related changes in meat tenderness and tissue pentosidine: Effect of diet restriction and aminoguanidine in broiler breeder hens. Poultry Sci. In review.

Kohn, R.R. 1983. Effects of age and diabetes mellitus on cyanogen bromide digestion of human dura mater collagen. Connect Tissue Res. 11:169-173.

Kohn, R.R., and Schnider, S.L. 1982. Glycosylation of human collagen. Diabetes 31:47-51.

Kohn, R.R., Cerami, A., and Monnier, V. 1984. Collagen aging in vitro by nonenzymatic glycosylation and browning. Diabetes 33:57-59.

Kristal, B., and Yu, B. 1992. An emerging hypothesis: Synergistic induction of aging by free radicals and Maillard reactions. J. Gerontology: Biol. Sci. 47:B107-B114.

Kristal, B.S., Park, B.K., and Yu, B.P. 1996. 4-Hydroxyhexenal is a potent inducer of the mitochondrial permeability transition. J Biol. Chem. 271:6033-6038.

Ku, H., and Sohal, R.S. 1993. Comparison of mitochondrial prooxidant generation and antioxidant defenses between rat and pigeon: possible basis of variation in longevity and metabolic potential. Mech. Aging Dev. 72:67-76.

.Laganiere, S., and Yu, B.P. 1993. Modulation of membrane phospholipid fatty acid composition by age and food restriction. Gerontology 39:7-18.

Le Pape, A., Guitton, J.D., Muh, J.P. 1984. Distribution of non-enzymatically bound glucose in vivo and in vitro glycosylated Type I collagen molecules. FEBS Lett.170:23-27.

Lyons, T.J., Bailie, D.E., Dyer, D.G., Dunn, J.A., and Baynes, J.W. 1991. Decrease in skin collagen glycation with improve glycemic control in patients with insulin-dependent diabetes mellitus. J Clin. Invest. 87:1910-1915.

Masoro, E.J. 1988. Food restriction in rodents: An evaluations of its role in the study of aging. J Gerontol. Biol. Sci. 43:B59-B64.

Masoro, E. J., Katz, M.S., Mcmahan, C.A. 1989. Evidence for the glycation hypothesis of aging from the food restricted rodent model. J. Gerontol. 44:B20-B22.

Masoro, E.J., and McCarter, R.J.M. 1991. Aging as a consequence of fuel utilization. Aging Clin. Exp. Res. 3:117-128. 
Masters, B.S.S. 1994. Nitric oxide syntheses: Why so complex? Annu. Rev. Nutr. 14:131-145.

Monnier, V.M, and Cerami, A. 1981. Nonenzymatic browning in vivo: possible process for aging of long lived proteins. Science 211:493.

Monnier, V.M., Kohn, R.R., and Cerami, A., 1984. Accelerated age-related browning of human collagen in diabetes mellitus. Proc. Nalt Acad Sci USA 81:583-587.

Monnier, V.M., Vishwanath, V., Frank, K.E., Elmets, C.A., Dauchot, P., and Kohn, P.R. 1986. Relationship between complications of type I diabetes mellitus and collagen-linked fluorescence. N. Engl. J. Med. 314:403-408.

Monnier, V.M. 1989. Toward a Maillard reaction theory of aging. In: The Maillard Reaction in Aging, diabetes and Nutrition, Prog. Clin. Biol. Res., Baynes, J.W. and Monnier, V.M., Eds., Alan R. Liss, New York.

Monnier, V.M., Sell, D.R., Abdul-Karim, F.W., and Emancipator, S.N. 1988. Collagen browning and crosslinking are increased in chronic experimental hyperglycemia. Diabetes 37:867-872.

Monnier, V. M. 1989. Toward a Maillard reaction theory of aging. Prog. Clin. Biol. Res. 304:1-22.

Monnier, V. M. 1990. Nonenzymatic glycosylation, the Maillard reaction and the aging process. J. Gerontol: Biol. Sci. 45, B105-B111.

Monnier, V.M., Sell, D.R., Nagaraj, R.H., Miyata, S. 1991. Mechanisms of protection against damage mediated by the Maillard reaction in aging. Gerontology 37:152-165.

Nagaraj, R.H., Timothy, T.S., Sell, D.R., Fogarty, J., Engerman, R.L., and Monnier, V.M. 1996. Evidence of a glycemic threshold for the formation of pentosidine in diabetic dog lens but not in collagen. Diabetes 45:587-594.

Nolen, G.A. 1972. Effect of various restricted dietary regimens on the growth, health, and longevity of albino rats. J. Nutr. 102:1477-1494.

Pierrefiche, G., and Laborit, H. 1995. Oxygen free radicals, melatonin, and aging. Experimental Gerontology. 30:3/4:213-227.

Reiser, K.M. 1991. Nonenzymatic glycation of collagen in aging and diabetes. Proc. Soc. Exp. Biol. Medl 196: 17-29.

Reiser, K. M., 1991 Nonenzymatic glycation of collagen in aging and diabetes. Prec. Soc. Exp. Biol. Med. 196:17-29.

Reiser, K.M., McCormick, R. and Rucker, R.B. 1992. Crosslinking in collagen and elastin. FASEB J. 6:2439-2449. 
Robins, S.P. 1982. Analysis of the crosslinking components in collagen and elastin. Meth. Biochi. Analysis 28:330-379.

Sabatino, F., Masoro, E.J., McMahan, A., and Kuhn, R.W. 1991. Assessment of the role of the glucocorticoid system in aging processes and in the action of food restriction. J. Gerontol. Biol. Sci. 46:B171-179.

SAS Institute, 1990. SAT/STAT7 Users Guide: Statistics. Release 6.04, SAS Institute Inc., Cary, NC.

Sell, D.R. and Monnier, V.M. 1989. Structure elucidation of a senescence crosslink from human extracellular matrix: Implication of pentoses in the aging process. J. Biol. Chem. 264:21597-21602.

Sell, D.R., and Monnier, V.M. 1990. End-stage renal disease and diabetes catalyze the formation of a pentose-derived crosslink from aging human collagen. J. Clin. Invest. 85:380-384.

Sell, D.R., Lapolla, A., Odetti, P., Fogarty, J,. and Monnier, V.M. 1992. Pentosidine formation in skin correlates with severity of complications in individuals with long-standing IDDM. Diabetes, 41:1286-1291.

Sell, D.R., Lane, M.A., Johnson, W.A., Masoro, E.J., Mock, O.B., Reiser, K.M., Fogarty, J.F., Cutler, R.G., Ingram, D.K., Roth, G.S., and Monnier, V.M. 1996. Longevity and the genetic determination of collagen glycoxidation kinetics in mammalian senescence. Proc. Natl. Acad. Sci. 93:485-490.

Sell, R. And Monnier, V. M. 1997. Age-related association of tail tendon break time with tissue pentosidine in DBA/2 vs C57BL/6 mice: the effect of dietary restriction. J. Gerontol: Biol. Sci. 52A:B277-B284.

Sohal, R.S., and Allen R.G. 1990. Oxidative stress as a causal factor in differentiations and aging: A unifying hypothesis. Exp. Gerontol. 25, 499-522.

Sohal, R.S., Agrawal, S., Dubey, A., and Orr, W.C. 1993. Protein oxidative damage is associated with life expectancy of houseflies. Proc. Natl. Acad, Sci. USA 90:7255-7259.

Weindruch, R., and Walford, R.L. 1982. Dietary restriction in mice beginning at 1 year of age: Effect of life-span and spontaneous cancer incidence. Science 215a;1415-1418.

Weindruch, R., and Walford, R.L. 1988. The retardation of aging and disease by dietary restriction. Springfield, IL Charles C Thomas.

Yamauchi, M., and Mechanic, G.L. 1987. Crosslinking of collagen. In: Nimni, M. E., ed. Collagen: vol. I. Biochemistry. Boca Raton, FL: CRC Press.

Youngman, L.D., Park, J.Y., K., and Ames, B.N. 1992. Protein oxidation associated with aging is reduced by dietary restriction of protein or calories. Proc. Natl., Acad. Sci. 89:9112-9116. 
Yu, B.P., Masoro, E.J., Murafa, I., Berfrand, H.Q and Lynd, F.T. 1982. Life-span study of SPF Fisher 344 male rats fed ad libitum or restricted diets: longevity, growth, lean body mass and disease. J. Gerontol.: Biol. Sci. 37:130.

Yu, B.P. 1993. Oxidative damage by free radicals and lipid peroxidation in aging. In: Yu, B.P., ed. Free radical in aging. Boca Raton, FL: CRC Press:57-88. 
Name

Place of Birth

Date of Birth

Parents

Spouse \& Children

High School

University

Work Experience

Professional Association

Permanent Address
Dinesh Singh Rathore

Maudha, Farrukhabad, India

June 23, 1953

Kushal Pal Singh

Sheelwati Devi

Sunita

Siddhartha, son

Malvika, daughter

Christ Church School, 1972

Lucknow, India,

B.S., Veterinary \& Animal Husbandry, 1976

G.B. Pant University of Agric. \& Tech.

Pantnagar, India

M.S., Poultry Husbandry, 1978

G.B. Pant University of Agric. \& Tech.

Pantnagar, India

Mohan Meakin Brewaries Limited

Mohan Nagar, India

1978-81

Central Sheep \& Wool Research Institute, Kodaikanal, India

1981-1986

Central Drug Research Institute

Lucknow, India

1987-

American Association for Laboratory

Animal Science

Laboratory Animal Science Association of India, founder member

B 2814

Indira Nagar

Lucknow: 226016

India 